\title{
Pharmaceutical Particle Engineering via Spray Drying
}

\author{
Reinhard Vehring ${ }^{1,2}$
}

Received August 30, 2007; accepted October 9, 2007; published online November 28, 2007

\begin{abstract}
This review covers recent developments in the area of particle engineering via spray drying. The last decade has seen a shift from empirical formulation efforts to an engineering approach based on a better understanding of particle formation in the spray drying process. Microparticles with nanoscale substructures can now be designed and their functionality has contributed significantly to stability and efficacy of the particulate dosage form. The review provides concepts and a theoretical framework for particle design calculations. It reviews experimental research into parameters that influence particle formation. A classification based on dimensionless numbers is presented that can be used to estimate how excipient properties in combination with process parameters influence the morphology of the engineered particles. A wide range of pharmaceutical application examples-low density particles, composite particles, microencapsulation, and glass stabilization-is discussed, with specific emphasis on the underlying particle formation mechanisms and design concepts.
\end{abstract}

KEY WORDS: dispersibility; microencapsulation; particle formation; respiratory drug delivery; stabilization.

\section{INTRODUCTION}

Many solid dosage forms in the pharmaceutical and biotech industries are based on microparticles. Dry powders are inhaled as aerosols into the lung, delivered to the nose, filled into capsules, or pressed into tablets for oral applications, or even delivered transdermally. In the past, microparticles were often viewed simply as carriers, usually micronized dry material, without sophisticated attributes. The primary functions of the micronization and drying processes were to achieve a suitable particle size and remove most of the solvent. This perspective has changed as novel drug delivery strategies were developed. More advanced therapeutic approaches have created complex requirements for dosage forms that can only be met by particles that are designed for a range of functions such as stabilization of the active, transport and targeting of the dose, or release modulation. The particle is no longer seen as a passive carrier, but rather as an essential part of the drug delivery system.

Particle Engineering is a young discipline that combines elements of microbiology, chemistry, formulation science, colloid and interface science, heat and mass transfer, solid state physics, aerosol and powder science, and nanotechnology. It provides the theoretical framework for a rational design of structured microparticles. Particle engineering requires a deeper understanding of particle formation processes. Complex structured microparticles are difficult to

\footnotetext{
$\overline{{ }^{1} \text { Particle Engineering, Pearl Therapeutics, Inc., } 200 \text { Saginaw Drive, }}$ Redwood City, CA 94063, USA.

${ }^{2}$ To whom correspondence should be addressed. (e-mail: rvehring@ pearltherapeutics.com)
}

design using an empirical approach alone because of the many process and formulation variables that need to be tuned correctly to achieve the desired result.

Efforts to understand and control particle formation processes were intensified in the last decade, coinciding with the development of pulmonary therapeutics that were traditionally given by injection (1-3). The pulmonary route was found to be viable for systemic delivery of proteins and peptides (4-6), in particular insulin (7-18), triggering the development of diverse administration systems and particle engineering strategies (19-28).

Microparticles can be manufactured by many different processing methods. This review focuses exclusively on spray drying (29-35), with an emphasis on the literature of the last five years. Wet chemistry and phase separation processes and alternative drying processes such as spray freeze drying, or supercritical fluid technologies, have also been used widely for particle engineering purposes and have been reviewed elsewhere (36-41).

\section{DEFINITIONS AND THEORY}

The purpose of this section is to clarify the terminology needed for a discussion of particle engineering. It will also provide equations that can be used to describe particle properties and the particle formation process. A rigorous treatment of the physics and chemistry that form the foundation of particle engineering is beyond the scope of this review and the reader is referred to several textbooks $(29,42-$ $45)$ that cover this material in more detail. Rather, this section will focus on working equations that can be used to link material properties and process parameters to particle, aerosol, or powder properties and the resultant product 
attributes. An engineering approach is used, relying on dimensionless numbers, and approximate expressions are presented where the exact equations are cumbersome to use.

\section{Terminology of Structured Microparticles}

Particle morphology can be described in terms of particle size, shape, internal structure, and surface properties. The terminology used in the literature to describe structured microparticles is inconsistent; this review suggests the following:

A core is the innermost part of the particle. It can be covered by one or more layers that are defined by having distinct composition or properties. A shell is an outer layer that is capable of bearing enough mechanical stress to influence or determine the morphology of the particle. In contrast, a coat is a thin layer incapable of providing structural rigidity. The schematic in Fig. 1b shows an idealized layered sphere with internal structure, comprising a core, a second layer, a shell and a coat. In Fig. 1a the core is replaced with a central void.

Particles can also have the cellular structure of solid foams, shown schematically in Fig. 1c and e. In contrast to voids, which are simply gas-filled space, cells are defined by a surrounding layer such as a membrane. Foam physics terminology can be used to describe the characteristics of the cellular material: in the case of a closed cell structure (Fig. 1c) the membranes of adjoining cells remain mostly intact, while in an open cell structure (Fig. 1e) the membranes have ruptured, leaving a network of struts behind which are called Plateau borders. The cells can be described as the dispersed phase and the interstitial matter between the cells as the continuous phase. Colloid science terminology is also applicable to particles that were created from suspensions of solids. Fig. 1d and f show schematic examples where the dispersed phase consists of smaller solid particles, typically nanoparticles. Two cases of particles are shown; a carrier particle where a significant fraction of the particle mass is in the continuous phase with few embedded smaller particles, and the opposite case of a particle with most of the mass in the dispersed phase. In the latter case the nanoparticles have formed a composite shell. A large number of small, homogenously dispersed, solid nanoparticles give the particle the nature of a sol. Embedded nanoparticles or liquid nanodroplets may have a coat or membrane at the solid-solid or liquid-solid phase interface. The latter case, a gel particle, is often called a dry emulsion in the literature (46-48). Fig. $1 \mathrm{~g}$
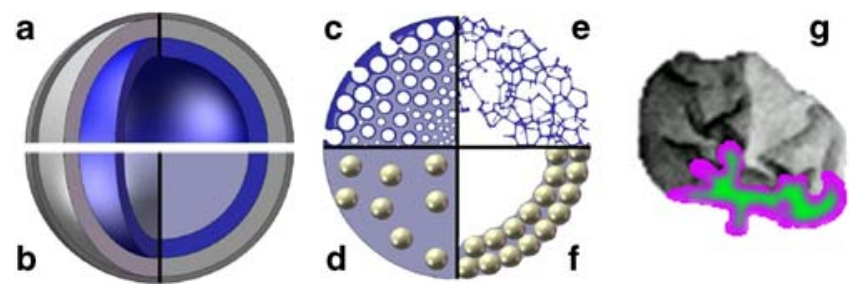

Fig. 1. Schematic representation of particle morphologies. a Layered with central core. b Layered with central void. c Solid foam, closed cell. d Solid foam, open cell. e Particle with embedded nanoparticles. f Composite shell. g Irregular, with external voids and internal concentration gradients. shows a particle with internal composition gradients which has an irregular surface forming external voids. The term irregular is used for particles whose primary form deviates significantly from that of a perfect sphere, such as indented or wrinkled particles. Irregular particles may still be spherical, i.e. their aspect ratio may be close to one.

\section{Particle Size}

With few exceptions, spray dried particles are spherical and their size can be described by their geometric diameter. This is an important parameter which influences the forces particles experience in fluid flows and the packing of particles when they form a powder. The geometric diameter is also often used as a reference, because it is in principle directly accessible by ultramicroscopic techniques.

However, the measurement of geometric diameters by image analysis is not without difficulties. One is rarely interested in the size of just a single particle, but rather the size distribution of all particles in a product. In the context of pharmaceutical applications the mass fraction of a particulate dosage form in a certain particle size interval is often sought. This information can be obtained by image analysis of a sample of the dose, but care has to be taken to ensure that a representative, statistically relevant sample is analyzed. Usually, this can only be accomplished with the help of automated microscopy and image analysis (49). Image analysis techniques generate count-based distributions that have to be converted to a mass-based distribution, e.g. with the help of the Hatch Choate equations (44).

The geometric diameter of particles that are not perfect spheres depends on their orientation. In this case an average geometric diameter can be substituted, e.g. by averaging Feret's horizontal and vertical diameters (50). If this is carried out on a large number of particles that are randomly oriented, the reported geometrical diameter is the orientation averaged Feret's diameter.

Other common particle sizing techniques do not measure the geometric diameter directly, but rather derive it from the behavior of the particles in response to the probe used in the analysis. The reported diameters are often confused with geometric diameters, but are in fact equivalent diameters specific to the analytical technique (49). A common example is an optical-equivalent diameter where particles are probed by a light source. Their scattering or absorption behavior is compared to that of a reference geometry, usually a homogeneous sphere. The geometric diameter of the reference sphere is only representative of the diameter of the sample particle if the optical properties of the sample are close to that of the reference. For structured or irregularly shaped particles this is often not the case, as can easily be recognized considering the variety of particle types shown in Fig. 1. The optical particle size for these particles is in reality a function of their geometric diameter and their secondary morphological features $(51,52)$. Equivalent particle diameters based on other properties or behavior such as electrical mobility, diffusion, sedimentation, surface or volume to surface ratio are used frequently and are described in the literature $(49,53)$.

An equivalent diameter of particular importance to respiratory delivery is the aerodynamic diameter, i.e. the 
diameter of a unit-density sphere that has the same settling velocity as the measured particle.

$$
d_{a}=\sqrt{\frac{\rho_{P}}{\rho^{*}}} d_{g}
$$

Equation 1 is a simplified description, valid for spheres in the continuum regime. Treatment and corrections for nonsphericity and transition regime flow can be found in the aerosol science literature $(44,49,54)$. The particle density, $\rho_{\mathrm{P}}$, in this equation should not be mistaken for the true density of the dried material. The particle density is the mass of the particle divided by the volume of a sphere of diameter $d_{\mathrm{g}}$ and can be significantly lower than the true density, because it includes internal and external voids.

It is straightforward to express the geometric diameter of spray dried, spherical particles as a function of formulation and process variables. The geometric diameter of the dry particle follows from a simple mass balance (55)

$$
d_{\mathrm{g}}=\sqrt[3]{\frac{c_{\mathrm{F}}}{\rho_{\mathrm{P}}}} d_{\mathrm{D}}
$$

This equation shows that the geometric diameter can be most effectively controlled by the atomization which determines the diameter of the droplets, $d_{\mathrm{D}}$. Particle size is also directly affected by changes in the concentration of the feed solution, $c_{\mathrm{F}}$. If Eqs. 1 and 2 are combined the resulting expression

$$
d_{\mathrm{a}}=\sqrt[6]{\frac{\rho_{\mathrm{P}}}{\rho}} \sqrt[3]{\frac{c_{\mathrm{F}}}{\rho^{*}}} d_{\mathrm{D}}
$$

shows that the aerodynamic diameter is also primarily determined by the feed solution concentration and the initial droplet diameter. Although somewhat counterintuitive, it is only a weak function of particle density, which only becomes important if it is significantly lower than unit-density. This explains the current trend to particles of very low density on the order of $0.1 \mathrm{~g} / \mathrm{cm}^{3}$ in pulmonary delivery, where a small aerodynamic diameter is desirable. Equation 3 also cautions that changes in the droplet size distribution, which may be encountered during process scale-up, or increases in the feed concentration, often initiated to improve the economics of the process, can cause a significant change in the aerodynamic properties of the particles.

Atomizer performance directly influences the particle size of the dried particles. Four different types of atomizers are used for the majority of industrial spray drying applications; rotary atomizers, pressure nozzles, two-fluid nozzles $(29,56)$, and ultrasonic atomizers $(57,58)$. Typical droplet mass median diameters in pharmaceutical spray dryers range from less than $10 \mu \mathrm{m}$ for pulmonary applications to upwards of $100 \mu \mathrm{m}$, which translates to a typical dry particle diameter range of 0.5 to $50 \mu \mathrm{m}$. Atomizer performance as a function of solution properties and operating conditions has been described elsewhere (29).

\section{Distribution of Components in Spray Dried Particles}

The key to successful particle engineering is understanding and controlling the mechanisms that determine the radial distribution of components during the drying process. Several different driving forces that may be responsible for separation of components have been suggested. Surface activity may lead to preferential adsorption of components on the droplet surface, causing a diffusional flux toward the surface. On the other hand, as the evaporating droplet shrinks its receding droplet surface leads to increasing solute concentrations at the surface. This causes a diffusional flux away from the surface (59). The diffusional motion inside an evaporating droplet must be correctly described to predict the resulting radial distribution of the individual components.

The evaporation of a solution droplet in a spray dryer is a coupled heat and mass transport problem. The process is driven by the difference between the vapor pressure of the solvents and their partial pressure in the gas phase. The rate of evaporation is determined by the balance of energy required to vaporize the solvent and the energy transported to the surface of the droplet. Various numerical models have been presented and reviewed (60-62) that describe the evaporation of multicomponent droplets in detail. Here a simplified analytical treatment is summarized.

In the absence of internal convection the distribution of the chemical components in an evaporating droplet can be described by the non-linear diffusion equation. For constant diffusion coefficients and negligible interactions between the solutes the diffusion equation becomes Fick's second law of diffusion (42). This equation in its one-dimensional, radially symmetric form has an analytical solution, if the droplet evaporates at a constant evaporation rate (63). The evaporation rate, $\kappa$, is defined as $(43,64)$

$$
d^{2}(t)=d_{0}^{2}-\kappa t
$$

The droplet surface area decreases linearly with time. This equation can also be used to approximate the droplet drying time (64) which should be smaller than the residence time of the droplets in the dryer to allow completion of drying.

$$
\tau_{D}=\frac{d_{0}^{2}}{\kappa}
$$

The solution of the diffusion equation can be rearranged so that it yields the surface enrichment, $E_{\mathrm{i}}$, which is the surface concentration of component $\mathrm{i}$ in relation to its average concentration in the droplet (50)

$$
E_{i}=\frac{c_{s, i}}{c_{m, i}}=\frac{\exp \left(0.5 P e_{i}\right)}{3 \beta_{i}}
$$

Here a dimensionless Peclet number, $P e$, has been used to simplify the equation:

$$
P e_{i}=\frac{\kappa}{8 D_{i}}
$$

$\beta$ is a function that must be integrated numerically for each Pe number to obtain an exact solution (50). However, an 
approximate expression for Eq. 6 with an accuracy of $\pm 1 \%$ in the range $\mathrm{Pe}<20$ can be used instead:

$$
E_{i}=\frac{c_{s, i}}{c_{m, i}}=1+\frac{P e_{i}}{5}+\frac{P e_{i}^{2}}{100}-\frac{P e_{i}^{3}}{4,000}
$$

The average concentration follows from a mass balance.

$$
c_{m, i}=c_{0, i}\left(1-\frac{t}{\tau_{D}}\right)^{-\frac{3}{2}}
$$

With these equations, the surface concentrations of the components can be predicted at any time in the evaporation process as a function of their Peclet number. A very useful parameter, $\tau_{\mathrm{sat}, i}$, the time for a component to reach saturation at the surface, can now be derived.

$$
\begin{gathered}
\tau_{\mathrm{sat}, i}=\tau_{\mathrm{D}}\left(1-\left(S_{0, i} E_{i}\right)^{\frac{2}{3}}\right) \\
S_{0, i}=\frac{c_{0, i}}{c_{\mathrm{sol}, i}}
\end{gathered}
$$

where the initial saturation of the components, $S_{0, i}$, is the second dimensionless parameter that directly influences the particle formation process.

Components may not crystallize immediately when their solubility limit is reached at the surface. Further characteristic times are associated with crystal nucleation, crystal growth, and polymorph transitions. For components that do not readily crystallize these characteristic times are frequently longer than the "precipitation window" defined by

$$
\tau_{p, i}=\tau_{D}-\tau_{\text {sat }, i}=\frac{d_{0}^{2}}{\kappa}\left(S_{0, i} E_{i}\right)^{\frac{2}{3}} .
$$

In this case a fully or partially amorphous solid is formed. Here another parameter becomes useful: $\tau_{\mathrm{t}, \mathrm{i}}$, the time it would take a component to reach a concentration at the surface that is equal to its true density in the dry state. While this is obviously a hypothetical case in a multi-component droplet, this characteristic time can still be used for a rough estimate of the time at which an amorphous shell at the surface is formed.

$$
\begin{gathered}
\tau_{t, i}=\tau_{D}\left(1-\left(P_{0, i} \cdot E_{i}\right)^{\frac{2}{3}}\right), \\
P_{0, i}=\frac{c_{0, i}}{\rho_{t, i}}
\end{gathered}
$$

The characteristic times given above are useful for particle design, because they allow an estimate of the sequence of precipitation events at the surface and the time that is available for crystallization of components. The equations can only be evaluated if a reasonable estimate for the droplet evaporation rate can be found. Calculation of evaporation rates as a function of the processing parameters is not a trivial problem in a realistic spray dryer. Here a simple approximation is given that uses the following equation (45) for single droplet evaporation

$$
\kappa=8 D_{g} \frac{\rho_{g}}{\rho_{l}}\left(Y_{s}\left(T_{e}\right)-Y_{\infty}\right) .
$$

Please see Table I for nomenclature. Although it neglects Stephan flow (65), this expression is still a good approximation as long as the partial pressure of the evaporating solvent remains small, i.e. for droplet temperatures that are much lower than the boiling point of the solvent. At high droplet temperatures the effects of Stephan flow should be included. Adequate expressions for the latter case are given in the literature $(43,50,66)$. To find the mass fraction at the surface of the droplet, $Y_{\mathrm{s}}$, the equilibrium temperature, $T_{\mathrm{e}}$, of the evaporating droplet must be determined. This can be done by iteratively solving the equation

$$
\frac{\Delta \widehat{H} v}{\hat{c}_{p}}=-\frac{L e \cdot\left(T_{\infty}-T_{e}\right)}{Y_{s}\left(T_{e}\right)-Y_{\infty}}
$$

in combination with a Clausius-Clapeyron relationship. The Lewis number, $L e$, is the ratio of the thermal diffusivity and the mass diffusivity in the gas phase (42). However, in the most common case of droplets evaporating in dry air or nitrogen the iteration can be avoided and the problem becomes very simple. A useful first approximation for the equilibrium temperature is an empirical correlation (60) for the wet bulb temperature of the droplet as a function of gas temperature, $T_{\mathrm{G}}$, and boiling temperature of the solution, $T_{\mathrm{b}}$.

$$
T_{\mathrm{wb}}=137\left(\frac{T_{\mathrm{b}}}{373.15}\right)^{0.68} \log \left(T_{\mathrm{G}}\right)-45
$$

Once the droplet temperature is determined, the vapor pressure or mass fraction at the surface of the droplet can be found using an Antoine equation (50) or tabulated data. Finally, the evaporation rate follows according to Eq. 13, and the Peclet numbers and the characteristic times for the components can be calculated. Frequently, no data is available for the diffusion coefficients of the solutes, but an estimate based on the Stokes-Einstein equation is usually sufficient.

Several corrections, e.g. for droplet-droplet interactions or for convective flow around the drying droplets would need to be introduced to describe the actual situation in a spray dryer. Adequate models describing droplet evaporation in spray dryers have been developed in combustion research (67) and the food industry $(68,69)$. Modeling of flow fields in spray dryers has been accomplished (34). The usefulness of the simple approach presented here lies in its potential to provide a quick overview of general trends for a particular particle design problem. It allows an assessment of the relative importance of various process parameters and material properties. This treatment cannot describe the processes that occur during the solidification of the particles, such as precipitation or buckling of shells (70), and it does not account for surface activity. However, it can approximate the radial distribution of all components prior to solidification. This may be predictive of the structure of the dry particle, as has been pointed out in an excellent study on the drying of 
Table I. Nomenclature

\begin{tabular}{|c|c|}
\hline Variable & Definition \\
\hline$c_{\mathrm{F}}$ & Feed solution concentration \\
\hline$c_{0, i}$ & Initial concentration, component $i$ \\
\hline$c_{s, i}$ & Surface concentration, component $i$ \\
\hline$c_{s o l, i}$ & Solubility, component $i$ \\
\hline$c_{m, i}$ & Average concentration, component $i$ \\
\hline$c_{p}$ & Specific heat capacity, solvent vapor \\
\hline$d$ & Diameter \\
\hline$d_{0}$ & Initial diameter \\
\hline$d_{\mathrm{a}}$ & Aerodynamic diameter \\
\hline$d_{\mathrm{D}}$ & Droplet diameter \\
\hline$d_{\mathrm{g}}$ & Geometric diameter \\
\hline$E_{\mathrm{i}}$ & Surface enrichment, component $i$ \\
\hline$D$ & Diffusion coefficient, liquid phase \\
\hline$D_{\mathrm{g}}$ & Diffusion coefficient, gas phase \\
\hline Le & Lewis number \\
\hline $\mathrm{P}_{0}$ & Initial density ratio \\
\hline $\mathrm{Pe}$ & Peclet number \\
\hline$t$ & Time \\
\hline$T_{\mathrm{b}}$ & Boiling temperature \\
\hline$T_{\mathrm{e}}$ & Equilibrium temperature, droplet \\
\hline$T_{\mathrm{G}}$ & Drying gas temperature \\
\hline$T_{\mathrm{wb}}$ & Wet bulb temperature \\
\hline$T_{\infty}$ & Gas temperature far away from droplet \\
\hline$S_{0}$ & Initial saturation \\
\hline$Y_{\mathrm{S}}$ & Mass fraction of solvent at surface \\
\hline$Y_{\infty}$ & Mass fraction of solvent far from surface \\
\hline$\Delta H_{\mathrm{v}}$ & Standard enthalpy change of vaporization \\
\hline$\beta$ & Profile function \\
\hline$\rho^{*}$ & Reference density, $1 \mathrm{~g} / \mathrm{cm}^{3}$ \\
\hline$\rho_{\mathrm{t}}$ & True density \\
\hline$\rho_{\mathrm{P}}$ & Particle density \\
\hline$\rho_{\mathrm{g}}$ & Drying gas density \\
\hline$\rho_{\mathrm{l}}$ & Droplet density \\
\hline$k$ & Evaporation rate \\
\hline$\tau_{\mathrm{D}}$ & Characteristic droplet drying time \\
\hline$\tau_{\text {sat }}$ & Characteristic time to saturation \\
\hline$\tau_{\mathrm{p}}$ & Characteristic time for precipitation \\
\hline$\tau_{\mathrm{t}}$ & Characteristic time to true density \\
\hline
\end{tabular}

milk powder (59). Hence, this model allows an estimate of which component is likely to act as a shell former.

A comprehensive theoretical description of particle formation during spray drying has not been published. The drying process of micro-droplets proceeds through nonequilibrium states where material properties are frequently unknown and experimentally difficult to access. Therefore, much of what is known about microparticle drying has been derived experimentally. It is worthwhile to review the experimental techniques that have been used to study droplet evaporation and particle formation. When interpreting the results of these studies it is important to consider the inherent limitations of the particular methods.

\section{PARTICLE FORMATION}

\section{Experimental Techniques}

Various experimental techniques for the investigation of droplet drying and particle formation have been introduced.
Studies using actual processing equipment are difficult to execute and interpret, because of the complexity of the twophase flow in spray dryers, the difficulty of installing adequate analytical instrumentation into a development dryer, and the large number of processing and formulation variables. Consequently, most of the techniques study more or less simplified systems that are models of the actual situation in a dryer.

Arguably the most simplified system is a single droplet in quiescent gas. Various levitation techniques, using optical, acoustic, or electrodynamic forces can be used to freely levitate single microdroplets $(71,72)$. Non-contact probing of the evaporating droplets allows measurement of evaporation rates with minimal interference. The shortcoming of the technique is in the time-scales that can be probed. It is difficult to introduce and levitate microdroplets in the experimental apparatus quickly enough to allow observation of a phenomenon with a characteristic time on the order of $10 \mathrm{~ms}$. Most studies on freely levitated droplets have used either larger droplets or liquids with very low vapor pressure that evaporate so slowly that the initial droplet capture and stabilization becomes short compared to the time of the measurement. A second disadvantage of this method is that shrinking and solidifying droplets experience a significant change in properties such as refractive index, charge state, or sphericity. This can lead to difficulties in maintaining a stable levitation until the end of the evaporation process.

An interesting variant of single droplet levitation uses the Leidenfrost phenomenon to trap droplets on a concave hot plate $(70,73)$. This technique was successfully used to study shell buckling during particle formation. A drawback of this approach is that the flow and temperature fields near the droplet are not similar to those of a free flowing droplet in a spray dryer.

The latter complication has been addressed by studying droplets suspended from thin filaments. This technique was used to observe the particle formation process of millimetersized droplets; particle density and morphology as a function of latent heat of crystallization, solubility, and drying rate were investigated (74). A recent study used a similar experimental set-up with an added capability to measure the surface adhesion of single, partially dry particles as a function of particle composition and moisture content (69). A refined filament suspension technique was applied to monitor the drying process of milk droplets (75-78). The morphology of dried particles was studied using suspended droplets for more than forty years (62,79-84), and much useful information has been derived from these studies. However, the use of a filament to suspend droplets has limitations. Heat and mass transfer can be affected by heat conduction between droplet and filament. The technique requires relatively large droplets, typically in the millimeter diameter range. This is problematic, because the processes involved in droplet drying scale differently with diameter. Droplet behavior observed on millimeter sized droplets may not be representative of microdroplets that are of interest in pharmaceutical applications.

Realistically sized droplets have often been studied in small scale spray dryers $(55,85)$. These studies have shed light on many individual aspects of the drying process. The importance of the ratio between droplet evaporation rate and diffusional motion of the solutes was recognized and the concept of the Peclet number has been used to explain low density particle morphology (86). It was also found that feed solution concentration (87) and solubility of the excipients 
affect particle morphology (88-90). Several studies show that precipitation kinetics and crystallization play an important role and may be affected by evaporation rate $(91,92)$. It has also been pointed out that drying temperature has a strong effect on particle morphology $(93,94)$.

Some researchers have used a chain of monodisperse free falling droplets to study heat and mass transfer, drying, and particle formation processes (80,95-98). With this technique the effect of drying rates on particle formation and the formation of internal voids in particles have been studied. The droplet generator commonly used in this technique produces closely spaced droplets, which may lead to droplet-droplet interactions (99-101), because the evaporation process is determined by gas phase transport processes. Furthermore, the studies were still carried out on relatively large droplets with a diameter $>170 \mu \mathrm{m}$ (102).

Recently, an improved droplet chain technique has been introduced (50) that is based on a droplet-on-demand generator. In this technique the droplet distance is a free variable and can be chosen so that droplets do not measurably interact. It is also capable of generating droplets in the diameter range useful for respiratory delivery. Basic particle formation mechanisms have been derived with this technique, which are categorized in the next section.

\section{Formation Mechanisms}

\section{Low Peclet number}

For Peclet numbers smaller than 1, the diffusional motion of the solutes is fast compared to the radial velocity of the receding droplet surface. In the absence of other driving forces, the solutes remain fairly evenly distributed in the droplet during the evaporation. The surface enrichment is small. If the solutes are freely soluble in the solvent, the initial saturation is also small and the characteristic time for the solutes to reach saturation at the surface is close to the droplet lifetime. In this case, solid particles with a particle density close to the true density of the dry components are likely to form. Typical examples are solid saccharide particles (103) dried at moderate to low drying gas temperatures, as shown in Fig. 2.

The Peclet number is influenced by a combination of material properties of the solute and the solvent and processing parameters that determine the evaporation rate. Even small molecules with comparatively large diffusion coefficients can be forced into significant surface enrichment with sufficiently large evaporation rates.

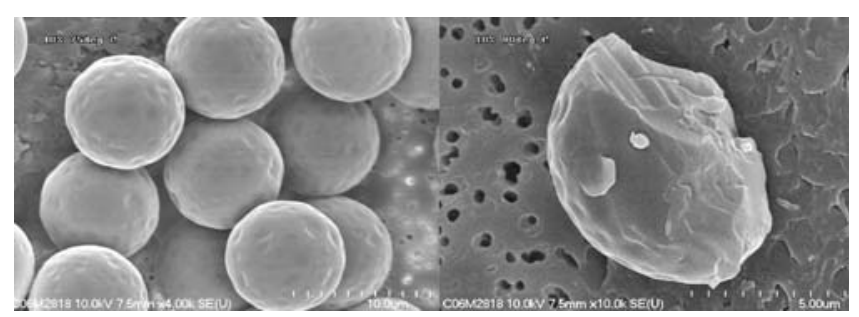

Fig. 2. Morphology of trehalose particles, spray dried from a custom benchtop spray dryer with monodisperse atomizer at drying rates between 1.7 and $4.1 \mu \mathrm{m}^{2} / \mathrm{ms}$. The particle on the right was intentionally crushed to reveal its internal structure.

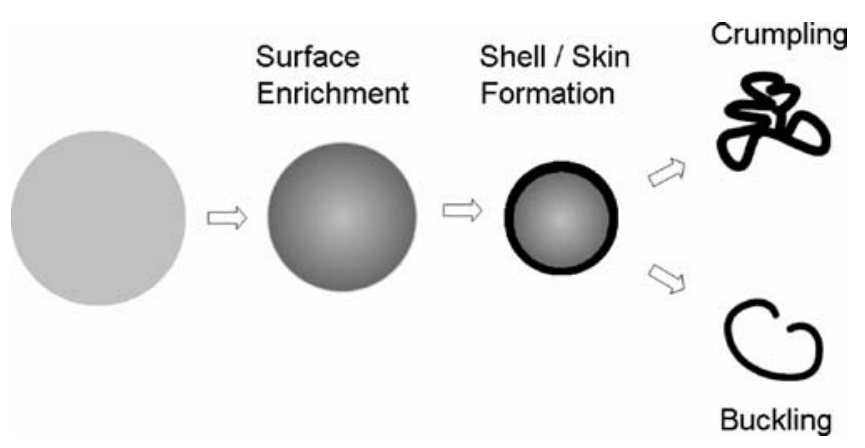

Fig. 3. Proposed particle formation process for high Peclet numbers.

Evidence for this can be found in hollow lactose particles that were dried in a bench-top spray dryer at relatively high inlet temperatures $(88,104,105)$. The processing parameters reported by the authors suggest a Peclet number larger than 1 , which is indicative of the particle formation mechanism described in the next section.

\section{High Peclet Number}

In the case of Peclet numbers larger than 1, schematically shown in Fig. 3, the surface moves faster than the dissolved or suspended components. The result is that the surface becomes enriched with the component associated with the high Peclet number. Depending on the nature of the component, different solidification mechanisms are triggered once a critical concentration at the surface is reached. Solutes may not have sufficient time to crystallize during the precipitation window. Instead, a shell may be formed due to the increase in viscosity as the solution transitions to a wet glass at the surface. Molecules with high initial saturation and fast crystallization kinetics may separate into a crystalline phase. Suspended material may form a composite shell. Regardless of the nature of the shell formation mechanism, the process is initiated at the surface. The resulting particles can have a range of different morphologies, depending on their size and the properties of their shells in the final stages of the drying process. Solid hollow spheres can be formed, if the shell becomes rigid quickly and does not buckle or fold. Otherwise, dimpled or wrinkled particles are formed.

The change of morphology as a function of Peclet number for a glycoprotein dried in a droplet chain technique is shown in Fig. 4. With increasing Peclet numbers the time to reach the critical concentration for shell formation at the surface decreases, i.e. shell formation occurs earlier in the evaporation process on a larger droplet. Hence, the density of the particle decreases.

Typical examples that fall into the category of high Peclet number particle formation are proteins and polymers. There are numerous examples in the literature reporting hollow and wrinkled or dimpled morphologies for spray dried protein $(50,92,106-110)$, peptide $(111,112)$ or polymer particles (57,90,113-118). An extreme case is the drying of droplets that contain suspended material such as nanoparticles $(86,119)$. Compared to the receding droplet surface the suspended material can be considered as immobile. The resulting surface accumulation and formation of a thin shell are intuitive in this case. 

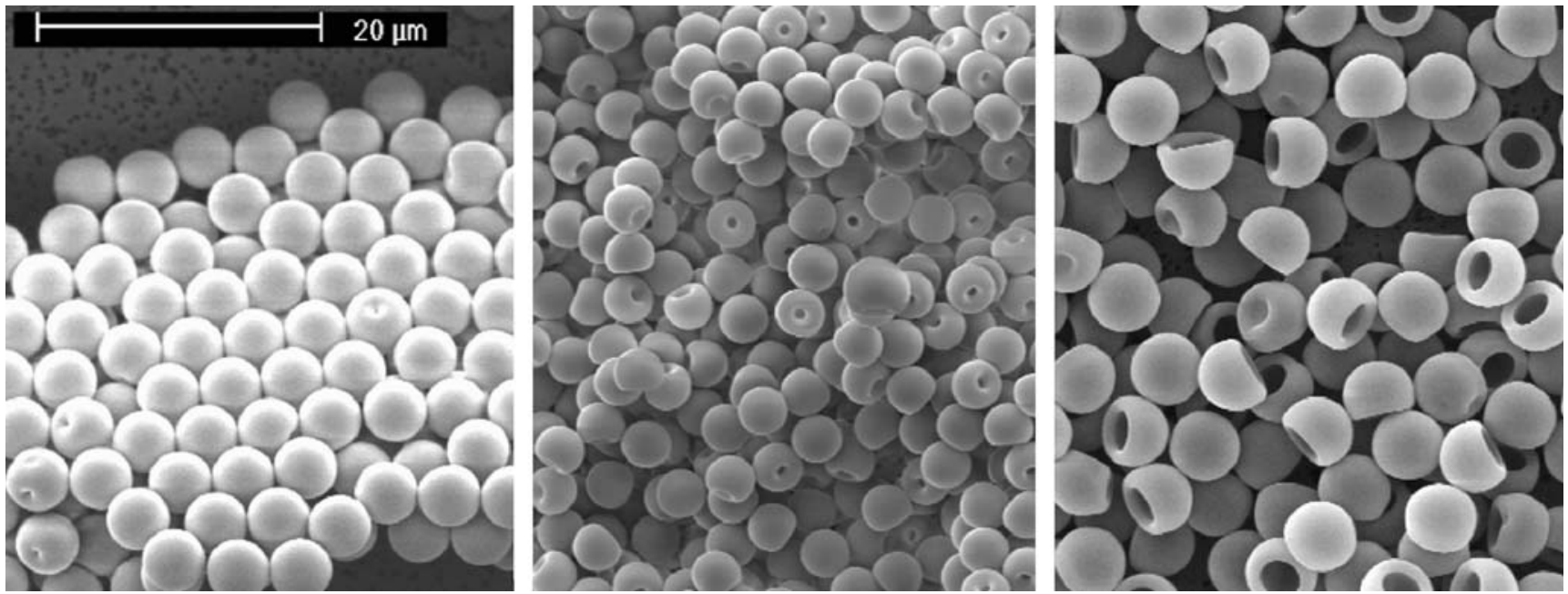

Fig. 4. Morphology of monomorph, monodisperse glycoprotein particles, produced by a droplet chain technique in dry air at drying temperatures of 25,50 , and $125^{\circ} \mathrm{C}$, from left to right, corresponding to Peclet numbers of $2.7,5.6$, and 16.8 respectively.

\section{Changing Peclet Number}

The discussion in the preceding section is very simplified. It assumes a constant evaporation rate and a diffusion coefficient that does not change with time or location in the droplet. In reality, the diffusion coefficient of a component changes with concentration and composition of the solvent. Hence, the Peclet number changes as the droplet evaporation progresses, in particular in co-solvent systems, where one solvent evaporates faster than the other. The Peclet number associated with a component in a formulation system can also change drastically, when the component undergoes a phase transition, e.g. crystallizes once a critical concentration is reached. This case is shown schematically in Fig. 5. Here a molecule with low solubility is dried that has a large diffusion coefficient, so its Peclet number is low initially. The concentration increases without much surface enrichment until supersaturation is reached and precipitation of a separate phase is initiated at the surface or throughout the bulk of the droplet. At this point the mobility of this component is no longer determined by the diffusion coefficient of the dissolved molecule, but rather by the much lower mobility of the phase separated domains. The Peclet number associated with this component is now very large and the phase separated domains accumulate at the surface and merge to form a shell which may deform in various ways, subsequently. Typical excipients that fall into this class

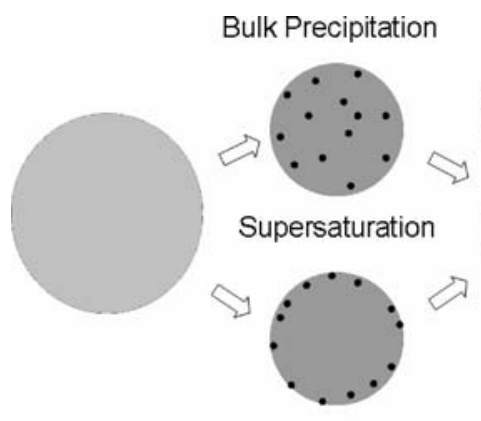

Surface Precipitation

Fig. 5. Proposed particle formation process for changing Peclet numbers. are low solubility amino acids or small peptides that have a propensity to crystallize or form liquid crystals.

A striking example for this type of formation mechanism is shown in Fig. 6. The electron micrograph shows hollow sodium chloride particles that were spray dried with an initial saturation of about $0.3(120,121)$. The size of the salt crystals in the shell corresponds to the diameter of the dry particle. This indicates that the precipitation window is shorter for smaller droplets, and the crystals do not have time to grow to the same size as in the larger droplets (see Eq. 11).

\section{Open Questions}

Many questions regarding the details of particle formation in spray drying remain unanswered. What is the role of surface activity in shell formation? Can shell deformation be

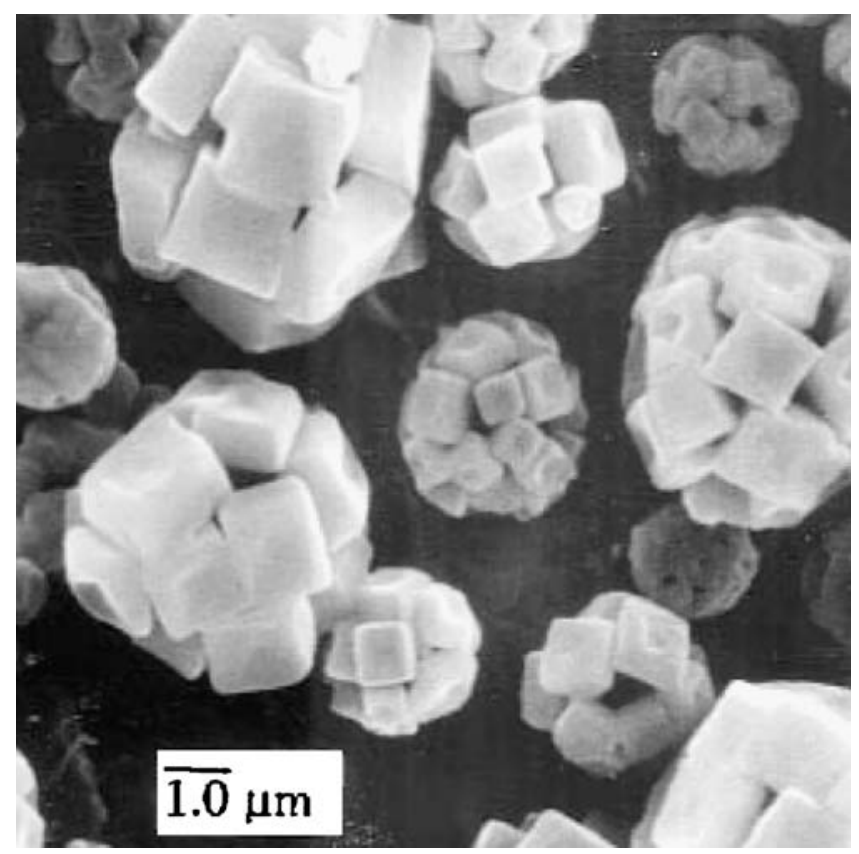

Fig. 6. Spray dried $\mathrm{NaCl}$ particles (With kind permission of AktivDry, Inc., Boulder, CO) 
controlled? Do microdroplets boil and inflate at high drying gas temperatures?

It has been pointed out many times that surface active molecules can replace other formulation components at the droplet surface and are detected in increased concentration at the surface of the dry particle (122-133). It was also shown that the addition of small amounts of surface active material can affect the particle morphology (108). Many of these studies have used Electron Spectroscopy for Chemical Analysis (ESCA) to analyze the surface composition of the dry particles. Because the penetration depth of ESCA is on the order of only $5 \mathrm{~nm}$ (134), it cannot be decided whether the predominant material on the surface identified by ESCA has formed a shell or has simply coated the particle. Other methods capable of probing the sub-surface composition, such as selective extraction of surface components or confocal microscopy, are being explored (135). Recently, it has been shown that the addition of a small amount of a surface active molecule, trileucine, improves the dispersibility of particles without changing the morphology of the particle (136). This indicates a coat on the surface affecting the cohesiveness of the particles. A larger amount of trileucine corresponding to a high initial saturation of 0.25 was necessary to change the morphology of the particle, which is in line with the formation mechanism shown in Fig. 5. The presence of an ordered surface layer may initiate or shorten the precipitation of the supersaturated solute and thus indirectly affect the particle morphology. However, it is not clear whether a surfactant with high solubility, dried at low Peclet numbers, is capable of forming a shell by a different mechanism than the ones described above. In summary, there is currently no consensus on the role of surface active material in particle formation (133).

After a shell has formed on an evaporating droplet, it is likely to be deformed by stress, due to pressure differences (73) and changes in material properties caused by desiccation or phase transformations. This period of the particle formation process determines whether a dry particle remains a hollow sphere, forms dimples, or folds on itself. Because the type of morphology affects important particle and powder properties such as cohesiveness or dispersibility $(107,137,138)$, it is desirable to understand and control shell deformation mechanisms. Theoretical approaches have been presented that describe the buckling of shells composed of nanoparticles (70) and the elastic deformation of polymer crusts on sessile drops (139). However, there is currently no comprehensive theoretical model and few experimental studies (140) to describe the shell deformation process on evaporating droplets in general. Studies are complicated by a severe lack of material properties in non-equilibrium states and the inability of current experimental methods to probe the process on realistic time and size scales.

It has been reported in the food drying literature (82) that large particles dried at gas temperatures above the boiling point of the solvent may inflate after shell formation due to build-up of internal gas pressure, potentially causing shell rupture or "blow-holes" in the shells. The author is not aware of any studies that directly observe this mechanism on droplets with a diameter on the order of $10 \mu \mathrm{m}$. Fig. 4 contains examples of particles dried above and below the boiling temperature of the solvent. Notably, the type of morphology does not change abruptly but rather continues a gradual trend to lower density. The associated optical size measurements show no evidence of inflation after shell formation (50). It can be concluded that the hole visible in these particles is not a "blow-hole" but rather a "sink-hole" caused by the drying of the droplet interior. It is unclear whether surface layers on small droplets pose sufficient diffusional resistance to impede evaporation enough so that the droplet temperature increases beyond the boiling temperature of the solvent. Even if that was the case, it is unclear whether droplet lifetimes on the order of milliseconds allow enough time for bubble nucleation. In addressing this question the size of the droplets and the scale of the spray dryer have to be considered carefully. This issue points to an inherent complication in spray drying; scale-up is not straightforward and may have significant effects on the morphology of the particles.

\section{APPLICATION EXAMPLES}

\section{Density Control}

Low density or hollow particles are advantageous for several applications, but specifically for pulmonary drug delivery where they improve dispersibility and delivery efficiency by lowering the aerodynamic diameter of the particles. Several particle design strategies have been developed to create voids in particles to lower the density. A hollow sphere can be created by using a shell forming excipient in combination with suitable processing conditions as described above. Irregular spherical particles may have external void space in folds or dimples. A corrugated surface further assists in dispersibility by minimizing contact areas. The design of such wrinkled particles is reviewed in the next section and creation of internal void space by alternative methods in the following paragraphs.

\section{Folded Shells}

Internal and external void space can be created by process conditions and formulations that cause early separation of a soft surface layer, which folds to form a wrinkled morphology. Early shell formation can be forced by choosing a high initial saturation, a high Peclet number, or a combination of both for the shell former.

The prominent formulation system in this class is known under the label "Large Porous Particles." The concept was introduced with polymer particles made by double- and single-emulsification solvent evaporation procedures followed by a freeze-drying step (141). Later the term "Large Porous Particles" became associated with particles that consist of dipalmitoylphosphatidylcholine (DPPC) in combination with albumin and saccharides spray dried from a sub-azeotropic ethanol-water co-solvent system (142-146).

DPPC has a very low aqueous solubility of $5 \mu \mathrm{g} / \mathrm{ml}$ or less (146) and its initial saturation can be adjusted by the ethanol water ratio. During the evaporation the DPPC saturation increases faster than the saturation of hydrophilic formulation components due to the preferential evaporation of ethanol and the associated change in the co-solvent ratio with time. The diffusion coefficient of DPPC is also low, in particular when it assembles into organized lipid structures. These properties point to a very early shell formation, which 
can be achieved on a comparatively large droplet, because the system is characterized by a low feed solution concentration, typically $0.1 \% \mathrm{w} / \mathrm{v}(142)$. Hence, the resulting particles have a very low particle density of typically less than $0.1 \mathrm{~g} / \mathrm{cm}^{3}$.

The experimental evidence in the literature points to DPPC as the primary shell forming excipient in this system. ESCA showed that the surface of particles consisting of albumin, DPPC and a saccharide was enriched in DPPC (147). Surface enrichment was reduced and particle density increased when the co-solvent ratio was shifted to higher ethanol content. This increased the solubility of DPPC which may have led to a decrease in initial DPPC saturation, delaying shell formation according to Eq. 10a, b. DPPC was capable of forming low density particles without the presence of albumin (86,147-149). Removing DPPC from the formulation system led to denser particles (149).

It was shown, however, that the amount of albumin in the formulation also has an effect on the morphology and density of the particles $(142,149)$. Albumin can change particle morphology and lower particle density $(107,122,138,150,151)$ and it can be expected that it has the potential to act as a shell former on its own $(85,132,152)$. Its low diffusion coefficient leads to large Peclet numbers at typical drying gas temperatures. Which shell former dominates the particle formation process depends on their characteristic times to reach a critical surface concentration and their interactions. Particle engineering using this formulation system relies on a proper selection of formulation and process variables, which affect the interaction and particle formation mechanisms of albumin and DPPC.

Large Porous Particles based on the DPPC-albumin formulation system have demonstrated excellent performance in DPI applications for pulmonary drug delivery. Emitted doses in the range of $90-100 \%$ from a passive dry powder inhaler were reported (149,153-155). Total lung deposition and dose variability were clearly superior compared to conventional DPI systems (154). It was hypothesized that DPPC may have membrane permeation enhancer properties, leading to increased bioavailability for peptides (153). These particles may further have the potential for sustained release in the lung $(143,145,146)$ due to the low aqueous solubility of the DPPC or avoidance of macrophage uptake (156). A variant of this formulation system, known as Lipid-ProteinSugar Particles, typically produces smaller particles by spray drying DPPC, albumin, and lactose from an ethanol-water co-solvent system. The primary role of the shell formers in this case is not the reduction of density, but the encapsulation of the active pharmaceutical ingredient. These particles have been suggested for sustained release applications of injectable therapeutics and anesthetics in various tissue targets (157-163).

Large Porous Particles are a part of the AIR ${ }^{\circledR}$ pulmonary drug delivery system (164-166) and have entered late stage clinical trials for insulin (167-169) and early human studies for parathyroid hormone $(155,170)$. They have been used to formulate human growth hormone (153), heparin (171), and small molecules such as albuterol sulfate (144), para-aminosalicylic acid (148), or levodopa (172).

\section{Solid Foam Particles}

A different approach to designing particles with very low particle density is to create a foam-like particle morphology.
The most advanced method in this category is trademarked under the label PulmoSpheres ${ }^{\mathrm{TM}}(173,174)$. These particles are produced by spray drying of an emulsion, in which the dispersed phase typically has a submicron droplet size and consists of a liquid that evaporates slower than the continuous phase. The dispersed phase is stabilized by phospholipids which hinder coalescence when the droplet shrinks due to the evaporation of the continuous phase. As a result the droplet stops shrinking when the nanodroplets of the dispersed phase are closely packed. The phase interfaces form a foam-like structure that desiccates and solidifies subsequently. Once the liquid of the dispersed phase has evaporated, the space occupied by the former nanodroplets remains as voids, leaving a solid foam that provides the desired reduction in particle density (175). An example is shown in Fig. 7.

A comprehensive theoretical description of the formation process for this type of particle has not been published. Spray drying of emulsions has been an intensive area of research in food science, specifically regarding the drying of dairy products. However, a consensus about the mechanisms of emulsion dehydration has not been reached (176). The problem is complex, because several competing sub-processes with similar time-scales need to be considered. The motion of the emulsion nanodroplets causes convective flow in the droplet, the problem cannot be treated as one-dimensional, and momentum conservation cannot be neglected. Still, the lack of diffusional mobility of the dispersed phase may play a role in the particle formation. It has been reported $(175,177)$ that increasing concentration of the dispersed phase leads to the formation of a central internal void of increasing volume, which is consistent with the diffusion controlled particle formation mechanism described above.

In the case of PulmoSpheres ${ }^{\mathrm{TM}}$ the dispersed phase typically consists of perfluorooctylbromide (PFOB) $(178,179)$ stabilized with distearoylphophatidylcholine (179-181) or a similar phospholipid (175). The properties of the phospholipid can be optimized using calcium chloride $(179,181,182)$. The active pharmaceutical ingredient is typically dissolved in the continuous phase if it has sufficient aqueous solubility. The continuous phase may also contain additional excipients such as hydroxyethylstarch (183).

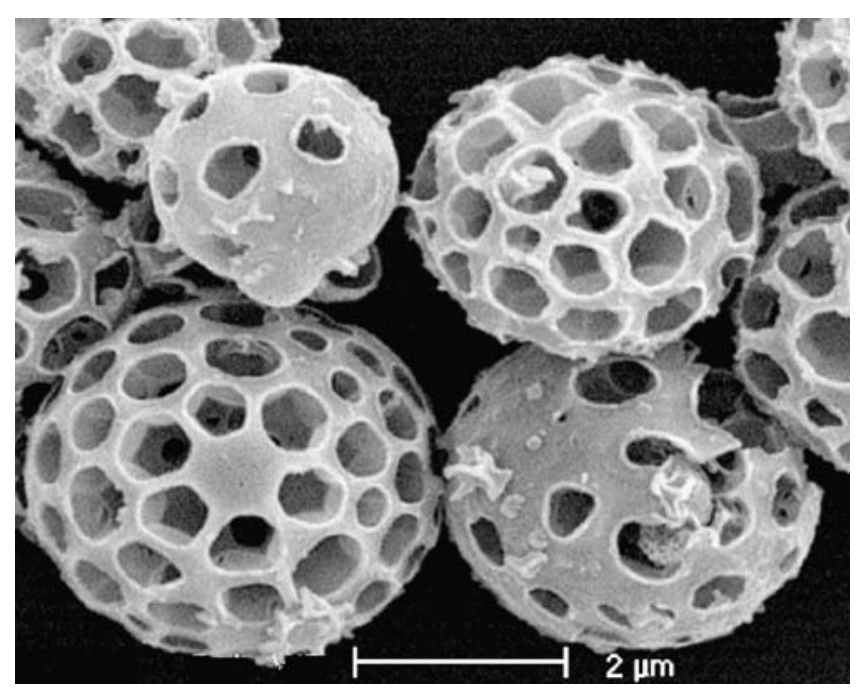

Fig. 7. PulmoSpheres ${ }^{\mathrm{TM}}$ solid foam particles. 
Alternatively, poorly soluble molecules may be incorporated into the PulmoSpheres ${ }^{\mathrm{TM}}$ particles as smaller separate crystalline particles. In the suspension-based PulmoSpheres ${ }^{\mathrm{TM}}$ manufacturing process $(181,184)$, the active is dispersed in the form of micro- or nanocrystals in the continuous phase of the emulsion. This complex suspension is then spray dried and particles are formed that either have the character of carrier particles (180), if the crystals are small enough to be embedded in the typical solid foam structure of the PulmoSpheres ${ }^{\mathrm{TM}}$, or are composite particles (184). In the latter case the phospholipid has been shown to form a coat on the dispersed material which provides improved dispersibility. Lipid coating of micronized material can alternatively be achieved by spray drying from a lipid solution in which the microcrystals are suspended (185).

PulmoSpheres ${ }^{\mathrm{TM}}$ were originally developed as ultrasound contrast medium (186) and have been administered to the lung by liquid instillation (187-189). They have been applied to pulmonary delivery of several small molecules and peptides (178-180) and have been suggested for vaccination purposes $(183,190,191)$, modulation of immune responses (192) or immunoglobulin delivery (193). The performance of these advanced particles in dry powder inhalers $(178,180)$ or metered dose inhalers $(179,194,195)$ has been shown to significantly exceed that of conventional dosage forms. In a study on pulmonary delivery of tobramycin, the authors found that the delivery of the active using PulmoSpheres ${ }^{\mathrm{TM}}$ was nine times as efficient as delivery by a nebulizer (178). A study on budesonide reported a two-fold efficiency advantage relative to a conventional powder formulation (180).

The PFOB used in the manufacturing process of PulmoSpheres ${ }^{\mathrm{TM}}$ is often called a blowing agent, which is somewhat misleading, because its boiling point is higher than that of water. Hence, the role of this pore forming agent during the formation process is more that of a placeholder. The use of propellants with much higher vapor pressure than water as the dispersed phase in a formulation system otherwise similar to that of PulmoSpheres ${ }^{\mathrm{TM}}$ has been attempted (196). The resulting particles also have very low particle density but posses a morphology that is not foam-like. The formation mechanism for these particles has not been described in detail.

A related approach is the use of volatile salts as pore forming agents to create voids (197,198). Typical examples, termed pore forming agents in the associated literature, are ammonium carbonate (199) or ammonium bicarbonate (200). The volatile salt can be added in various ways to the droplets, as micronized solid in an organic solvent $(199,201)$, dissolved in water (202), or via the dispersed phase of a water-in-oil emulsion (203). Typically, the continuous phase or the organic solvent evaporates first, forming the initial particle morphology which incorporates the solid salt. The volatile salt is then sublimed, typically in a secondary drying or freeze drying step. If the formulation system is compatible with high drying gas temperatures, ammonium bicarbonate may also be removed directly during the spray drying process, as it sublimes at temperatures above $50^{\circ} \mathrm{C}$ (202).

Particles based on this formulation approach have been developed by Acusphere, Inc. as ultrasound contrast agents (203) and delivery vehicle for poorly soluble drugs (204). In this embodiment the continuous phase consists of a polymer, poly-lactide-co-glycolide or polyvinylpyrrolidone (200), and optionally a lipid, such as diarachidoyl-glycero-phosphocholine, dissolved in suitable solvents such as methylene chloride or ethanol (200). The continuous phase may also contain the active pharmaceutical ingredient. The dispersed phase is an aqueous ammonium bicarbonate solution.

\section{Microencapsulation}

The term microencapsulation has been used in various ways by researchers and developers in food and pharmaceutical sciences. It often simply means that a substance is incorporated into a microparticle and no further description of the particle structure and its effect on the performance of the product is attempted. While in the food industry microencapsulation is often associated with retention of flavor or aroma substances during drying and storage (205207), pharmaceutical applications usually apply microencapsulation to control the release, improve bioavailability, e.g. through mucoadhesion (208-211), or to mask the taste of an active pharmaceutical ingredient $(212,213)$. The term microencapsulation implies that particles have an outer layer that contains or protects the interior, but this is only one among several particle morphologies that have been reported. Encapsulation in a wider sense can also be accomplished with a homogeneous particle where the matrix itself delays dissolution and release, or with composite particles, where smaller embedded particles or capsules may be covered by additional layers with a barrier function (114,214-216).

Modulating the release of volatile or soluble components from a microparticle in the presence of an external driving force is a difficult task. The release rate from a microparticle is influenced by complex interactions between body fluids, the encapsulant, and the encapsulated material (217). Dissolution, erosion and diffusion of material in the particle not only depend on material properties such as solubility and diffusion coefficients, but also on the morphology of the particle. The rate of diffusion through a layer of encapsulant, for example, depends on its thickness and surface area. In the case of microparticles the layer thickness tends to be variable and on the order of $1 \mu \mathrm{m}$ or less, and the specific surface area is very large, in particular if pores are present. The small length scales associated with microparticles favor rapid release or an unacceptable burst effect unless the associated diffusion coefficients and solubilities are very low. Hence, materials investigated for microencapsulation of spray dried particles are typically high molecular weight, slowly biodegradable polymers such as polylactide $(89,114,118,214,218-224)$, polylactide-coglycolide, polycaprolactone (219,225-228), carbomers (229), and methacrylate copolymers $(213,230-237)$, or polysaccharides (238) such as chitosan $(215,216,229,239-257)$, cellulose derivatives $(132,213,215,216,229,237,243,245,258)$, and hyaluronan $(238,259)$, or cross-linked proteins (260). Polylactide-coglycolide, PLGA, has been studied most intensively and has been used to encapsulate small molecule $(94,117,220,224,261-$ $273)$ and protein $(58,219,274-280)$ therapeutics and various antigens $(218,223,227,281-287)$ for vaccination purposes.

Detailed reviews of different microencapsulation strategies for the purpose of controlled release and adjuvanticity in therapy and vaccination are available $(33,249,288-295)$. This review focuses on a different application of microencapsulation; the use of shells or coats to improve the dispersibility of powders for pulmonary delivery. One approach in particular 
has attracted significant attention, the use of leucine and trileucine as dispersibility enhancers.

\section{Leucine and Trileucine Particles}

Dispersibility is a powder property that still lacks a commonly accepted definition or measure. It is used to describe the degree of dispersion of a powder into individual particles or agglomerates upon exertion of an external dispersion force, e.g. an aerodynamic shear force, typically in a pulmonary delivery device such as a dry powder inhaler. The degree of powder dispersion is important, because it has significant impact on the respirable dose administered to the patient. Many particle parameters affect powder dispersibility; frequently mentioned are size distribution, density, morphology, surface energy, surface roughness, and surface hydrophobicity.

The traditional approach to improving the dispersibility of cohesive powders is to blend them with carrier particles or additives that modify the interparticle forces. Amino acids, lecithin, chitosan and magnesium stearate have been suggested for this purpose $(115,296)$. Among the amino acids, leucine stands out as particularly effective in improving flowability and dispersibility of powder blends $(297,298)$. Therefore, it appears promising to incorporate dispersibility enhancers such as amino acids $(115,299,300)$, specifically leucine, into the particles of a homogeneous powder to encapsulate cohesive material or improve the surface properties of the particles.

The formation mechanism for leucine particles can be derived from the published literature. Pure spray dried leucine forms hollow particles of low density $(301,302)$, demonstrating that leucine is capable of forming a shell, i.e. it has the potential to encapsulate if the particles are designed correctly. Leucine is a weak surfactant (303) with a low molecular weight of $131.17 \mathrm{~g} / \mathrm{mol}$. The initial Peclet number for typical drying conditions is small, because its diffusion coefficient in water or ethanol is large. However, the solubility of leucine in water is low, $22 \mathrm{mg} / \mathrm{ml}$, and even lower in ethanol. Consequently, if the initial saturation is sufficient, leucine is expected to reach supersaturation early in the drying process. Leucine may then crystallize, following the particle formation mechanism described above in the section about changing Peclet numbers.

Further support for this hypothesis comes from the finding that leucine is crystalline in spray dried pure leucine particles $(301,302)$, in particles consisting of leucine, a chelating agent and optionally a lipid (202), and in leucineepinephrine particles (304). However, if the initial saturation of leucine in the droplet is low, allowing another component to precipitate sooner, the leucine crystallization is expected to be inhibited, a case that was apparently encountered in a study (305) where a small amount of leucine was added to disodium cromoglycate at low initial leucine saturation of $S=$ 0.02 . No crystalline leucine was detected in this case. The initial saturation of leucine is evidently important, as shown in a study on tobramycin, where the dispersibility increased with increasing leucine content (306). Leucine is capable of encapsulating even large molecules such as polymers or antibodies if its initial saturation is high enough. This can be aided by spray drying from a water-ethanol co-solvent system where the solubility of leucine can be adjusted by changing the solvent ratio (307). An example of leucine-encapsulated protein particles is given in Fig. 8. In the electron micrograph below the initial leucine concentration, corresponding to an initial saturation of 0.25 , was sufficient to encapsulate the immunoglobulin particles. The particles shown above also contain a small amount of leucine, but the initial saturation of 0.09 was too low to change the morphology. The morphology of these particles is identical to that of pure immunoglobulin particles (not shown). This particle design concept has been used to improve the dispersibility of or encapsulate a variety of active pharmaceutical ingredients and vaccines, such as $\beta$ estradiol (308), follicle stimulating protein (309), plasmid DNA (310), or bacillus Calmette-Guérin vaccine (311).

The discussion above shows that encapsulation by leucine relies on a high initial saturation. This can be achieved in several ways that all have their specific disadvantages. A high concentration of the feed solution provides high initial saturation, but also increases the dry particle size, which is undesirable for pulmonary administration. A large fraction of leucine in the formulation can accomplish high initial saturation at lower feed solution concentrations, but is unfavorable for therapeutics that require a large dose, because it leads to a high powder mass and a large excipient
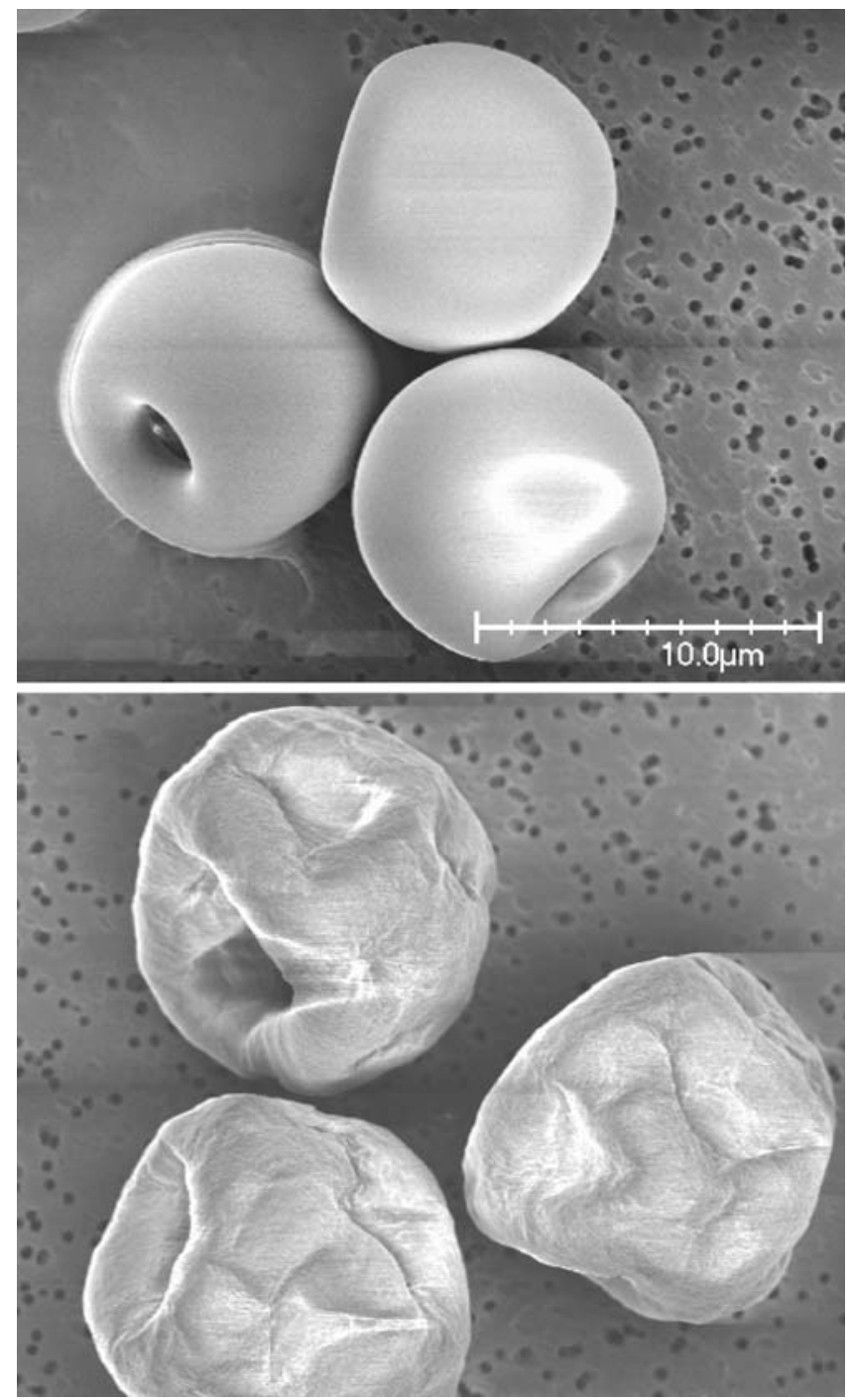

Fig. 8. Spray dried immunoglobulin particles. Above uncoated, below coated with leucine. 
load relative to the active. Spray drying from an ethanol water co-solvent system increases the complexity of the processing equipment and may not be compatible with all active pharmaceutical ingredients or other required excipients. An alternative approach is the use of a shell forming excipient that combines many properties of leucine with a lower aqueous solubility. This insight has lead to an investigation of di- and tripeptides as dispersibility enhancers and trileucine has emerged as particularly useful.

Compared to leucine, trileucine has a higher surface activity and a threefold lower solubility in water. It has been shown that trileucine indeed improved dispersibility at much smaller fractions in the formulation than a comparable leucine formulation in albuterol and salmon calcitonin formulations (312). Pure spray dried trileucine particles have ultra-low particle densities on the order of $0.1 \mathrm{~g} / \mathrm{cm}^{3}$ or less and the density does not depend strongly on the drying rate (50). The typical morphology of pure spray dried trileucine particles is shown in Fig. 9.

The morphology of raffinose, cromolyn, gentamicin, and netilmicin particles was changed to a rugose, low density type with the addition of only $15 \%$ trileucine (136,313). A key difference between leucine and trileucine particles is that spray drying of trileucine results in non-crystalline powders, indicating that trileucine precipitates into an amorphous or partially ordered phase (314). This gives trileucine the ability to participate in the stabilization of the active pharmaceutical ingredient, as has been demonstrated with human growth hormone (315). The role of particle engineering in stabilization of particulate dosage forms is discussed in more detail in the next section.

\section{Stabilization}

Every pharmaceutical product must remain efficacious and safe during its shelf life. For microparticle products this requirement tends to be complex, because not only the active and the excipients need to remain chemically stable, but also the physical stability of the dosage form must be accomplished. Microparticles produced by spray drying are often in an energetically unfavorable state, because of their large

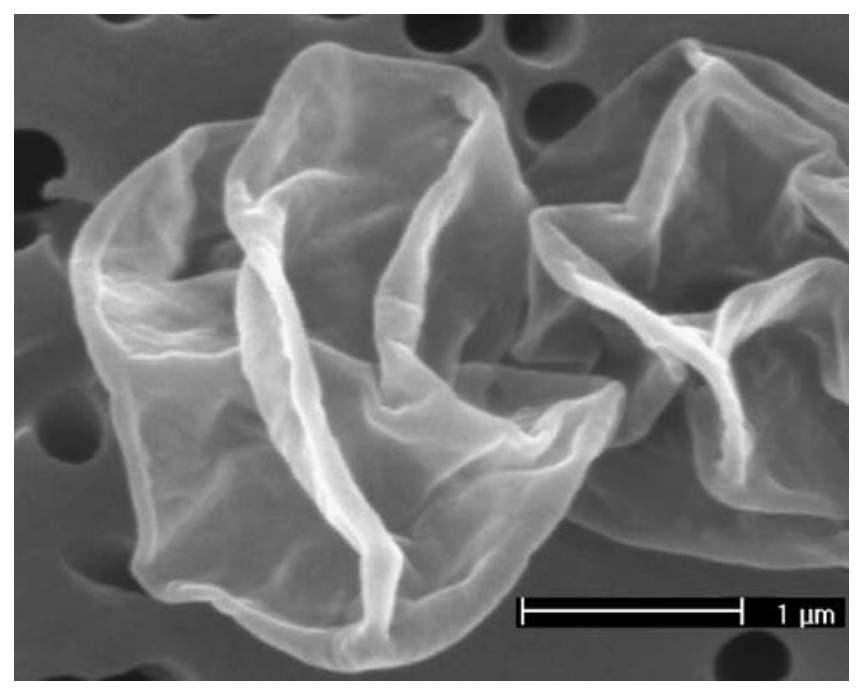

Fig. 9. Low density trileucine particles. surface area. Also, they frequently have not reached an equilibrium state, because of the short characteristic times of the drying process. Given sufficient mobility, microparticles tend to convert to an energetically more favorable state, either by crystallization (316-320), polymorph transition (321), crystal growth, or fusion of particles (322). All of these processes usually lead to product failure. Chemical stability can be lost through many routes depending on the nature of the active. Some adverse influences like light exposure or moisture and oxygen induced reactions can be mitigated through external protection, e.g. desiccants or oxygen scavengers. However, it is usually preferable to plan for chemical stability during particle design. For degradation that is driven by air-liquid interface exposure, aggregation, or unfolding of proteins there is no other viable option. For biotechnology application particle design also may need to consider biological stability of live organisms. The reader is referred to recent reviews for an introduction into the various stabilization approaches that have been developed (323) and the underlying concepts of physical forms of dry dosage forms $(41,314)$, specifically the nature of amorphous solids (324326). This review focuses on the particular issues arising in stabilization of spray dried microparticles.

Physical stability of microparticles can be accomplished by designing either a fully crystalline or an amorphous particle with high viscosity (327). Viscosity in an amorphous glass is characterized by the glass transition temperature. Amorphous glasses possess high viscosity if kept well below the glass transition temperature, which is typically designed to be 40 to $50^{\circ} \mathrm{C}$ above the storage temperature. This strategy, known as glass stabilization, has also been used to provide chemical stability for the active pharmaceutical ingredient, in particular for biologicals. Excipients used for glass stabilization are usually saccharides, polyols, or organic salts that form glasses of high viscosity. Embedding molecules in a rigid amorphous matrix slows degradation reactions by hindering translational motion, but it may not be sufficient to slow fast local rotational and vibrational motions of the molecules. A water replacement strategy may be necessary to achieve stability $(106,328)$. This strategy uses excipients capable of replacing the hydrogen bonds that were broken due to desiccation, or capable of slowing down fast dynamics in glasses. In case of cell or virus formulations, the situation is further complicated by the fact that the inside of the organism can only be protected if stabilizers are transported across its membrane and the difference between interior and exterior environment does not cause damage to the integrity of the cell or virus. Amino acid (35) and saccharide excipients such as glucose (329), sorbitol (106), lactose (330), sucrose (331$337)$, or trehalose $(106,125,182,282,283,332,334,337,338)$ have been found to be particularly effective in desiccoprotection and have been used in spray drying applications.

When designing stable microparticles manufactured by spray drying, one must consider several challenges that are specific to the microparticle formation process: As discussed above, components in a microparticle tend to separate due to their different diffusional velocities if their Peclet numbers are sufficiently different. It is clearly disadvantageous if stabilizers separate from the molecule they are supposed to stabilize. This mechanism has mostly been neglected in discussions about glass stabilization of microparticles. Rapid 
droplet evaporation tends to produce dry particles where the composition is a function of the radius. Hence, the glass transition temperature is also expected to be different for the core and the shell of a layered particle (84).

A second mechanism that can lead to unfavorable separation of components is surface activity. A surfactant that is successful in keeping air-liquid interface sensitive molecules away from the surface may unintentionally produce a coat with a low glass transition temperature on the surface that causes unacceptably high cohesive forces between the particles. Alternatively, a surface active protein may at least partially be enriched on the surface, leading to different stabilizer-protein ratios on the surface versus the core of the particle (131).

A third separation mechanism is the sequential precipitation of components due to their different characteristic times to saturation. The situation is further complicated by the fact that the precipitation window for typical spray drying applications is on the order of the characteristic times for crystal nucleation, crystal growth, or polymorph transitions.

A good example for this effect is the variety of physical forms of mannitol that have been observed in spray dried microparticles. Whether mannitol crystallizes during spray drying or subsequently on storage depends on several factors. In a salmon calcitonin-mannitol system the mannitol remained amorphous when the formulation contained less than $50 \%$ mannitol, but crystallized when more mannitol was added (321). Similar observations were made during the development of a spray dried monoclonal antibody. Mannitol crystallinity depended on formulation composition (182) and crystallization on stability could be retarded by adding an inhibitor (339). An insulin-mannitol formulation produced crystalline mannitol, whereas an otherwise similar RNAsemannitol formulation produced amorphous mannitol (340). The sensitivity of the mannitol crystallinity to composition and processing conditions can be explained by similar characteristic times for crystallization and droplet evaporation in typical pharmaceutical applications. This hypothesis is supported by the observation that different polymorphs and an amorphous mannitol fraction were simultaneously present in a salmon calcitonin-mannitol formulation at high mannitol fractions (321,341). According to the Ostwald step rule, crystallization is initiated by forming the least stable polymorph with subsequent transitions to the most stable form. However, if the process cannot proceed to equilibrium, because the loss of mobility occurs faster than the transition to the most stable form, the resulting solid state of the powder is a mixture of non-equilibrium states, which were arrested depending on the length of the precipitation window.

Partially crystalline systems or presence of more than one polymorph has also been observed for other spray dried substances like glycine (342), sucrose (34), polyethylene glycol and lactose $(343,344)$, cromolyn sodium (345), or acetazolamide (346). Particles may also have separated amorphous phases (347), a possible explanation for the destabilizing effect of sucrose at high sucrose to protein ratios. Partially crystalline systems in particular are undesirable for two reasons. Firstly, since the more stable solid form has already been nucleated, the tendency to convert the remaining less stable fraction during storage is increased. This may lead to inferior stability. Once the amorphous fraction starts to crystallize, the water contained in it is mostly expelled and increases the mobility in the remaining amorphous fraction through plasticization. This accelerates the crystallization (348), which usually causes rapid failure. Secondly, a solid dosage form whose physical state is sensitive to small changes in the timing of the drying process is hard to commercialize. Scale-up becomes very difficult, because the longer residence time typical for larger dryers is likely to alter the physical state and, thus the stability of the product (34).

The same mechanisms that lead to the challenges outlined above present opportunities, which can be exploited to design structured microparticles with unique properties. Because of the typically short precipitation window, crystallization of substances during spray drying often leads to very small crystals. While this can pose a stability risk due to the tendency of nanocrystals to grow on stability by an Ostwald ripening mechanism, the unique properties of nanocrystals can also be beneficial, e.g. leading to an increase in bioavailability (349) for low solubility molecules. Spatial separation of material with high and low viscosity can be used to design structured microparticles that possess much better physical stability than a homogeneous particle with the same composition. Typical examples are gel particles, known as dry emulsions, where liquid nanodroplets are stably encapsulated in an amorphous matrix with high glass transition temperature $(48,129)$. Another example of advanced glass stabilization is shown in Fig. 10. An active pharmaceutical ingredient with low glass transition temperature was physically and chemically stabilized in an amorphous,

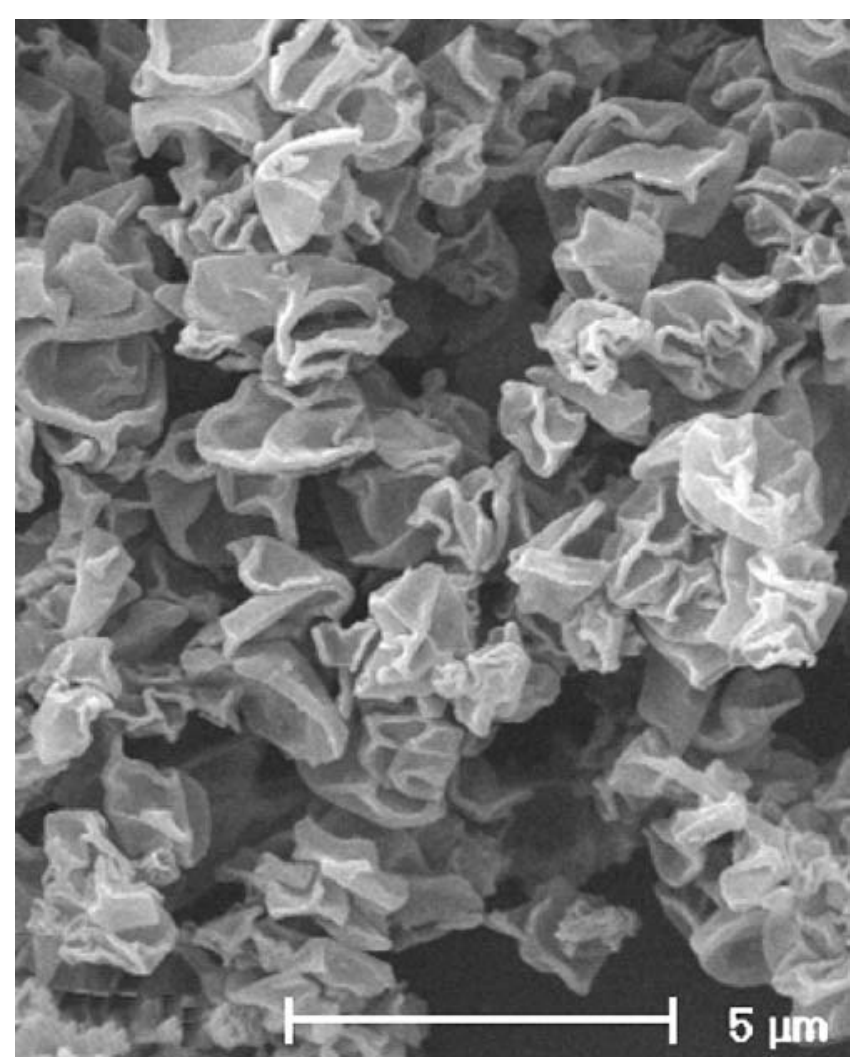

Fig. 10. Particles designed for high physical stability, containing $56 \%$ of an encapsulation agent forming the shell, $20 \%$ saccharide, $20 \%$ active pharmaceutical ingredient with low glass transition temperature, and $4 \%$ inorganic salt. 
structured microparticle. The glass transition temperature of the homogeneously mixed formulation was estimated to be suppressed to approximately $5^{\circ} \mathrm{C}$ at the $60 \% \mathrm{RH}$ stress condition due to plasticization. The storage temperature was at least $20^{\circ} \mathrm{C}$ above the glass transition temperature, which in theory should lead to physical instability of the powder in a matter of minutes. On the contrary, the aerosol performance of this powder was still largely unchanged after 7 days of exposure. The most likely explanation for this observation is that the particles have a core-shell structure like the one shown in Fig. 1g. The calculation of the glass transition temperature assumed a well-mixed glass and a homogeneous particle, while in reality the particle had a core with low viscosity encapsulated by a stable shell of high viscosity. Exceptional physical stability of the powder was the result.

Glass stabilization was introduced to spray dried microparticles by Nektar Therapeutics, San Carlos, CA, and became known under the trademark PulmoSolTM $(8,22)$. The most prominent product in this category is Exubera ${ }^{\circledR}$ (350-352), the first inhalable insulin for the management of diabetes. The spray dried powder used in Exubera ${ }^{\circledR}$ consists of insulin in a buffered formulation of stabilizers. It contains $60 \%$ recombinant human insulin, sodium citrate, glycine and mannitol (12,353). The fully amorphous (354) particles have a glass transition temperature of approximately $115^{\circ} \mathrm{C}$ when completely dry, and of $78-95^{\circ} \mathrm{C}$ when the moisture content is within storage specifications (351). Physical and chemical stability is excellent, providing 2 years of shelf life at room temperature (355). Comparing the molecular weights of the excipients shows that insulin has the highest Peclet number in this formulation. Considering its high initial concentration in the formulation, the theory presented in this review predicts that insulin is the main shell former and the particles will likely have the typical wrinkled or dimpled protein morphology. Indeed, the Exubera powder morphology shows external voids on particles with a folded shell (351, 356) and is nearly identical to that of pure spray dried insulin (112). These particles have been thoroughly tested in various human trials during the development of Exubera ${ }^{\circledR}$. Pharmacology, efficacy and safety of the product have been reviewed extensively $(9,27,355,357,358)$.

\section{Outlook}

The examples given in this review show the level of sophistication that can be achieved with a seemingly simple process such as spray drying. Even spray drying from a homogeneous solution, if properly understood, can be used to design particles that have a multifunctional internal structure. Potential further advances in particle engineering may be achieved by combining spray drying with additional processing steps before, during, or after the drying step.

The most common modification to a simple solution spray drying process is the preparation of a suspension or colloid prior to spray drying. Two-phase systems are often necessary because of solubility limitations of active and excipients, but they are also employed to transfer some of the structural properties of the two-phase system onto the final dry particles. A typical example is spray drying from an $\mathrm{o} / \mathrm{w}$ emulsion to manufacture PulmoSpheres ${ }^{\mathrm{TM}}$, where the droplet size of the dispersed phase influences the void size in the dried particles. Ordinary emulsions, mostly o/w emulsions (46-48), and immiscible aqueous (359) and non-aqueous (360) two-phase systems have been studied. Multiple emulsions have also been successfully spray dried, e.g. an $\mathrm{O} / \mathrm{W} / \mathrm{O} /$ W triple emulsion for the encapsulation of orange oil (361). Spray drying of sols (362-365) or suspended solids is a variation of this theme.

Again, the use of a solid dispersion is often dictated by poor solubility and the dispersed solid may simply be micronized or unprocessed material (366-371). Increasingly, though, the dispersed phase has been produced in yet another processing step and possesses specific properties that translate to the final dried particle. Dispersions of small unilamellar liposomes have been spray dried to produce highly dispersible powders for possible pulmonary delivery of superoxide dismutase (372). Spray dried suspensions of dextran microspheres (373) were investigated in the context of nasal drug delivery, pre-formed microcapsules were spray dried to encapsulate phase change materials (374), and dispersions of porous and non-porous silica micro and nanoparticles were spray dried in combination with indomethacin (375), tolbutamide (376), and simvastatin (377). DNA in combination with lyoprotectants was lyophilized, micronized, and subsequently spray dried as a solid-in-oil dispersion to achieve encapsulation in PLGA (378).

A very exciting development is the design of composite particles spray dried from dispersed nanoparticles $(51,52,70,73,86,119,365,379-384)$ or even mixtures of different nanoparticles (385). The nanoparticles are typically manufactured separately prior to preparation of the dispersion and retain their special properties such as enhanced solubility or targeting capacity for the final product. Some of their disadvantages, e.g. their tendency to agglomerate or their unfavorable aerosol transport properties, are mitigated by the fact that they are now part of a larger microparticle (382). It is interesting that the properties of the product are now determined by the primary morphology of the composite particle, the morphology of its nanoscale substructure, and their interactions. This highlights the importance of proper particle design in these systems.

Rather complex dispersion systems with more than one solid dispersed phase have been studied. Calcium salts were dispersed in an aqueous polymeric suspension and then spray dried to produce microencapsulated particles (386). A second example with multiple pre-processing steps is based on a complex dispersion of polymer nanoparticles and micronized fumed silica that was spray dried to produce nanoparticlecoated microparticles (387-393). In this system the drug may be associated either with the organic nanoparticle phase or the inorganic silicon dioxide phase. Several complex dispersions based on o/w emulsions with additional suspended solid material have also been tried. The solid dispersed phase consisted either of the micronized active $(181,184)$, precipitated ethylcellulose (216), or highly porous magnesium aluminometasilicate particles (394).

In the second class of modified spray drying additional steps are added during atomization or drying. Typical examples are atomizer nozzles that allow the mixing of fluids immediately prior to or simultaneous with the atomization process $(395,396)$, or multi-zonal drying chambers, where the droplet evaporation is followed by a secondary drying or firing step that can change the solid state of the particles (397) or remove placeholder material to create porosity $(382,398,399)$. 
Sophisticated processes, in which spray drying from complex dispersions is coupled with a multi-zonal dryer with three different temperature zones have been presented (400).

Lastly, post-processing steps can be added after spray drying. While secondary drying is common to adjust the moisture content of powder, more intricate processes such as microencapsulation (401) have also been proposed. Developments in the area of bioactive surface layers seem particularly promising. For example, the surface of spray dried microparticles has been loaded with covalently bonded antibodies (402) or adsorbed DNA $(403,404)$ for immunomodulation purposes.

A thorough review of the large number of combination processes where spray dried microparticles play a role is beyond the scope of this review. It will be interesting to follow whether the added functionality of the particles fabricated with such processes will justify their increased complexity in a commercial setting. It is already obvious that the new class of engineered spray dried particles requires a shift in the thinking and structure of pharmaceutical organizations developing them. Because both process and formulation now equally determine key product parameters, it should be reconsidered whether separate groups working on formulation and process development, optimization and scale-up are adequate. This new class of products demands a unified design approach reflected in an organizational structure that allows constant collaboration of formulators and process engineers in a single group. It also becomes evident that purely empirical approaches to product design are doomed to fail in a situation where the parameter space is defined by a very large number of formulation and process variables. Successful design of engineered particles requires thorough understanding and predictive modeling, so that the early development process can be completed in an acceptable time with a high likelihood of success. Much of the fundamental work, including the measurement of urgently needed material properties remains to be done.

\section{REFERENCES}

1. J. S. Patton and P. R. Byron. Inhaling medicines: delivering drugs to the body through the lungs. Nat. Rev. Drug Discov. 6:67-74 (2007).

2. R. Vanbever. Performance-driven, pulmonary delivery of systemically acting drugs. Drug Discov. Today Technol. 2:3946 (2005).

3. N. R. Labiris and M. B. Dolovich. Pulmonary drug delivery. Part II: the role of inhalant delivery devices and drug formulations in therapeutic effectiveness of aerosolized medications. Br. J. Clin. Pharmacol. 56:600-612 (2003).

4. H. Okamoto, H. Todo, K. Iida, and K. Danjo. Dry powders for pulmonary delivery of peptides and proteins. KONA 20:71-83 (2002).

5. K. A. Johnson. Preparation of peptide and protein powders for inhalation. Adv. Drug Deliv. Rev. 26:3-15 (1997).

6. J. D. Brain. Inhalation, deposition, and fate of insulin and other therapeutic proteins. Diabetes Technol. Ther. 9:S4-S15 (2007).

7. J. S. Patton, J. Bukar, and S. Nagarajan. Inhaled insulin. $A d v$. Drug. Deliv. Rev. 35:235-247 (1999).

8. J. R. White and R. K. Campbell. Inhaled insulin: an overview. Clin. Diabetes 19:13-16 (2001).

9. L. Fabbri. Pulmonary safety of inhaled insulins: a review of the current data. Curr. Med. Res. Opin. 22:S21-S28 (2006).

10. L. Heinemann, A. Pfützner, and T. Heise. Alternative routes of administration as an approach to improve insulin therapy: update on dermal, oral, nasal and pulmonary insulin delivery. Curr. Pharm. Des. 7:1327-1351 (2001).

11. L. Heineman and T. Heise. Current status of the development of inhaled insulin. Br. J. Diabetes Vasc. Dis. 4:295-301 (2004).

12. D. R. Owens, B. Zinman, and G. Bolli. Alternative routes of insulin delivery. Diabet. Med. 20:886-898 (2003).

13. T. Quattrin. Inhaled insulin: recent advances in the therapy of type 1 and 2 diabetes. Expert Opin. Pharmacother. 5:2597-2604 (2004).

14. I. A. Harsch. Inhaled insulins-their potential in the treatment of diabetes mellitus. Treat. Endocrinol. 4:131-138 (2005).

15. T. K. Mandal. Inhaled insulin for diabetes mellitus. Am. J. HealthSyst. Pharm. 62:1359-1364 (2005).

16. S. Ghosh and A. Collier. Inhaled insulins. Postgrad. Med. J. 83:178-181 (2007).

17. J. S. Skyler. Pulmonary insulin delivery—state of the art 2007. Diabetes Technol. Ther. 9:S1-S3 (2007).

18. D. B. Muchmore and J. R. Gates. Inhaled insulin deliverywhere are we now?. Diabetes Obes. Metab. 8:634-642 (2006)

19. D. A. Edwards and C. Dunbar. Bioengineering of therapeutic aerosols. Annu. Rev. Biomed. Eng. 4:93-107 (2002).

20. J. S. Patton, J. G. Bukar, and M. A. Eldon. Clinical pharmacokinetics and pharmacodynamics of inhaled insulin. Clin. Pharmacokinet. 43:781-801 (2004).

21. B. E. deGalan, S. Simsek, C. J. Tack, and R. J. Heine. Efficacy and safety of inhaled insulin in the treatment of diabetes mellitus. Neth. J. Med. 64:319-325 (2006).

22. J. G. Weers, T. E. Tarara, and A. R. Clark. Design of fine particles for pulmonary drug delivery. Expert Opin. Drug Deliv. 4:297-313 (2007).

23. S.-A. Cryan. Carrier-based strategies for targeting protein and peptide drugs to the lungs. AAPS J. 7:E20-E41 (2005).

24. K. Koushik and U. B. Kompella. Particle \& device engineering for inhalation drug delivery. Drug Deliv. Technol. 4:40-50 (2004).

25. A. X. C. N. Valente, R. Langer, H. A. Stone, and D. A. Edwards. Recent advances in the development of an inhaled insulin product. Biodrugs 17:9-17 (2003).

26. M. Sakagami and P. R. Byron. Respirable microspheres for inhalation: the potential of manipulating pulmonary disposition for improved therapeutic efficacy. Clin. Pharmacokinet. 44:263277 (2005).

27. R. Jani, C. Triplitt, C. Reasner, and R. A. DeFronzo. First approved inhaled insulin therapy for diabetes mellitus. Expert Opin. Drug Deliv. 4:63-76 (2007).

28. J. L. Selam. Inhaled insulin for the treatment of diabetes: projects and devices. Expert Opin. Pharmacother. 4:1373-1377 (2003).

29. K. Masters. Spray Drying-An Introduction to Principles, Operational Practice and Applications, Leonard Hill, London, 1972.

30. J. Broadhead, S. K. Edmond Rouan, and C. T. Rhodes. The spray drying of pharmaceuticals. Drug Dev. Ind. Pharm. 18:1169-1206 (1992).

31. P. Giunchedi and U. Conte. Spray-drying as a preparation method of microparticulate drug delivery systems: an overview. STP Pharma Sci. 5:276-290 (1995).

32. S. Wendel and M. Çelik. An overview of spray-drying applications. Pharm. Technol. 21:124-156 (1997).

33. M.-I. Ré. Formulating drug delivery systems by spray drying. Dry. Technol. 24:433-446 (2006).

34. T. A. G. Langrish. New engineered particles from spray dryers: research needs in spray drying. Dry. Technol. 25:981-993 (2007).

35. G. Lee. Spray-drying of proteins. Pharm. Biotechnol. 13:135158 (2002).

36. A. H. L. Chow, H. H. Y. Tong, P. Chattopadhyay, and B. Y. Shekunov. Particle engineering for pulmonary drug delivery. Pharm. Res. 24:411-437 (2007).

37. S. A. Shoyele and S. Cawthorne. Particle engineering techniques for inhaled biopharmaceuticals. Adv. Drug Deliv. Rev. 58:1009-1029 (2006).

38. M. N. V. Ravi Kumar. Nano and microparticles as controlled drug delivery devices. J. Pharm. Pharm. Sci. 3:234-258 (2000).

39. Y.-F. Maa and S. J. Prestrelski. Biopharmaceutical powders: particle formation and formulation considerations. Curr. Pharm. Biotechnol. 1:283-302 (2000). 
40. H.-K. Chan and N. Y. K. Chew. Novel alternative methods for the delivery of drugs for the treatment of asthma. Adv. Drug Deliv. Rev. 55:793-805 (2003).

41. H. H. Y. Tong and A. H. L. Chow. Control of physical forms of drug particles for pulmonary delivery by spray drying and supercritical fluid processing. KONA 24:27-40 (2006).

42. R. B. Bird, W. E. Stewart, and E. N. Lightfoot. Transport Phenomena, Wiley, New York, 2002.

43. N. A. Fuchs. Evaporation and Droplet Growth in Gaseous Media, Pergamon, London, 1959.

44. K. Willeke and P. A. Baron (eds.). Aerosol Measurement: Principles, Techniques, and Applications. Wiley, New York, 2001.

45. W. H. Finlay. The Mechanics of Inhaled Pharmaceutical Aerosols, Academic, San Diego, 2001.

46. G. Dollo, P. Le Corre, A. Guérin, F. Chevanne, J. L. Burgot, and R. Leverge. Spray-dried redispersible oil-in-water emulsion to improve oral bioavailability of poorly soluble drugs. Eur. $J$. Pharm. Sci 19:273-280 (2003).

47. G. Dollo, P. Le Corre, F. Chevanne, and R. Le Verge. Bupivacaine containing dry emulsion can prolong epidural anesthetic effects in rabbits. Eur. J. Pharm. Sci. 22:63-70 (2004).

48. K. L. Christensen, G. P. Pedersen, and H. G. Kristensen. Physical stability of redispersible dry emulsions containing amorphous sucrose. Eur. J. Pharm. Biopharm. 53:147-153 (2002).

49. B. Y. Shekunov, P. Chattopadhyay, H. H. Y. Tong, and A. H. L. Chow. Particle size analysis in pharmaceutics: principles, methods and applications. Pharm. Res. 24:203-227 (2007).

50. R. Vehring, W. R. Foss, and D. Lechuga-Ballesteros. Particle formation in spray drying. J. Aerosol Sci. 38:728-746 (2007).

51. H. Chang, and K. Okuyama. Optical properties of dense and porous spheroids consisting of primary silica nanoparticles. J. Aerosol Sci. 33:1701-1720 (2002).

52. H. Chang, K. Okuyama, and W. Szymanski. Experimental evaluation of the optical properties of porous silica/carbon composite particles. Aerosol Sci. Tech. 37:735-751 (2003).

53. F. M. Etzler and M. S. Sanderson. Particle size analysis: a comparative study of various methods. Part. Part. Syst. Charact. 12:217-224 (1995).

54. J. H. Vincent. Aerosol Science for Industrial Hygienists, Pergamon, Oxford, 1995.

55. Y.-F. Maa, P.-A. Nguyen, K. Sit, and C. C. Hsu. Spray-drying performance of a bench-top spray dryer for protein aerosol powder preparation. Biotechnol. Bioeng. 60:301-309 (1998).

56. M. Sacchetti, and M. M. Van Oort. Spray-drying and supercritical fluid particle generation techniques. In A. J. Hickey (ed.), Inhalation Aerosols, Physical and Biological Basis for Therapy, Vol. 94, Lung Biology in Health and Disease, Marcel Dekker, New York, 1996, pp. 337-384.

57. B. Bittner, and T. Kissel. Ultrasonic atomization for spray drying: a versatile technique for the preparation of protein loaded biodegradable microspheres. J. Microencapsul. 16:325-341 (1999).

58. S. Freitas, H. P. Merkle, and B. Gander. Ultrasonic atomisation into reduced pressure atmosphere — envisaging aseptic spray-drying for microencapsulation. J. Control. Release 95:185-195 (2004).

59. E. H.-J. Kim, X. D. Chen, and D. Pearce. On the mechanisms of surface formation and the surface compositions of industrial milk powders. Dry. Technol. 21:265-278 (2003).

60. R. S. Miller, K. Harstad, and J. Bellan. Evaluation of equilibrium and non-equilibrium evaporation models for many-droplet gasliquid flow simulations. Int. J. Multiph. Flow 24:1025-1055 (1998).

61. X. D. Chen. Heat-mass transfer and structure formation during drying of single food droplets. Dry. Technol. 22:179-190 (2004).

62. B. Adhikari, T. Howes, B. R. Bhandari, and V. Truong. Effect of addition of maltodextrin on drying kinetics and stickiness of sugar and acid-rich foods during convective drying: experiments and modelling. J. Food Eng. 62:53-68 (2004).

63. K. H. Leong. Morphological control of particles generated from the evaporation of solution droplets: theoretical considerations. J. Aerosol Sci. 18:511-524 (1987).

64. G. A. E. Godsave. Studies of the combustion of drops in a fuel spray-the burning of single drops of fuel. In Fourth Symposium (International) on Combustion, Williams and Wilkins, Baltimore, 1953, pp. 818-830.
65. F. R. Newbold and N. R. Amundson. A model for evaporation of a multicomponent droplet. AIChE J. 19:22-30 (1973).

66. D. B. Spalding. The combustion of liquid fuels. In Fourth Symposium (International) on Combustion, Williams and Wilkins, Baltimore, 1953, pp. 847-864.

67. W. A. Sirignano. Fluid Dynamics and Transport of Droplets and Sprays, Cambridge University Press, Cambridge, 1999.

68. M. Farid. A new approach to modelling of single droplet drying. Chem. Eng. Sci. 58:2985-2993 (2003).

69. B. Adhikari, T. Howes, and B. R. Bhandari. Use of solute fixed coordinate system and method of lines for prediction of drying kinetics and surface stickiness of single droplet during convective drying. Chem. Eng. Process 46:405-419 (2007).

70. N. Tsapis, E. R. Dufresne, S. S. Sinha, C. S. Riera, J. W. Hutchinson, L. Mahadevan, and D. A. Weitz. Onset of buckling in drying droplets of colloidal suspensions. Phys. Rev. Lett. 94: 018302 (2005).

71. E. J. Davis, P. Ravindran, and A. K. Ray. Single aerosol particle studies. Adv. Colloid Interface Sci. 15:1-24 (1981).

72. E. J. Davis and G. Schweiger. The Airborne Microparticle: Its Physics, Chemistry, Optics, and Transport Phenomena, Springer, Berlin, 2002.

73. Y. Sugiyama, R. J. Larsen, J.-W. Kim, and D. A. Weitz. Buckling and crumpling of drying droplets of colloid-polymer suspensions. Langmuir 22:6024-6030 (2006).

74. J.-C. Lin and J. W. Gentry. Spray drying drop morphology: experimental study. Aerosol. Sci. Tech. 37:15-32 (2003).

75. S. X. Q. Lin and X. D. Chen. Improving the glass-filament method for accurate measurement of drying kinetics of liquid droplets. Chem. Eng. Res. Des. 80:401-410 (2002).

76. S. X. Q. Lin, and X. D. Chen. Changes in milk droplet diameter during drying under constant drying conditions investigated using the glass-filament method. Food Bioprod. Process 82:213218 (2004).

77. X. D. Chen and S. X. Q. Lin. Air drying of milk droplet under constant and time-dependent conditions. AIChE J. 51:17901799 (2004).

78. X. Li, S. X. Q. Lin, X. D. Chen, L. Chen, and D. Pearce Inactivation kinetics of probiotic bacteria during the drying of single milk droplets. Dry. Technol. 24:695-701 (2006).

79. D. H. Charlesworth and W. R. Marshall Jr. Evaporation from drops containing dissolved solids. AIChE J. 6:9-23 (1960).

80. T. M. El-Sayed, D. A. Wallack, and C. J. King. Changes in particle morphology during drying of drops of carbohydrate solutions and food liquids. 1. Effects of composition and drying conditions. Ind. Eng. Chem. Res. 29:2346-2354 (1990).

81. J. M. Sunkel and C. J. King. Influence of the development of particle morphology upon rates of loss of volatile solutes during drying of drops. Ind. Eng. Chem. Res. 32:2357-2364 (1993)

82. D. E. Walton and C. J. Mumford. The morphology of spraydried particles The effect of process variables upon the morphology of spray-dried particles. Trans. Inst. Chem. Eng. 77A:442-460 (1999).

83. Y. Sano and R. B. Keey. The drying of a spherical particle containing colloidal material into a hollow sphere. Chem. Eng. Sci. 37:881-889 (1982).

84. B. Adhikari, T. Howes, B. R. Bhandari, and V. Truong. Surface stickiness of drops of carbohydrate and organic acid solutions during convective drying: experiments and modeling. Dry. Technol. 21:839-873 (2003).

85. K. B. Prinn, H. R. Costantino, and M. Tracy. Statistical modeling of protein spray drying at the lab scale. AAPS PharmSciTech. 3:1-8 (2002).

86. N. Tsapis, D. Bennett, B. Jackson, D. A. Weitz, and D. A Edwards. Trojan particles: large porous carriers of nanoparticles for drug delivery. Proc. Natl. Acad. Sci. USA 99:12001-12005 (2002).

87. T. A. G. Langrish, N. Marquez, and K. Kota. An investigation and quantitative assessment of particle shape in milk powders from a laboratory-scale spray dryer. Dry. Technol. 24:1619-1630 (2006).

88. J. E. Elversson, and A. Millqvist-Fureby. Particle size and density in spray drying-effects of carbohydrate properties. J. Pharm. Sci. 94:2049-2060 (2005). 
89. D. F. Bain, D. L. Munday, and A. Smith. Solvent influence on spray-dried biodegradable microspheres. J. Microencapsul. 16:453-474 (1999).

90. F.-J. Wang and C.-H. Wang. Sustained release of etanidazole from spray dried microspheres prepared by non-halogenated solvents. J. Control. Release. 81:263-280 (2002).

91. J. Raula, H. Eerikäinen, and E. I. Kauppinen. Influence of the solvent composition on the aerosol synthesis of pharmaceutical polymer nanoparticles. Int. J. Pharm. 284:13-21 (2004).

92. Y.-F. Maa, H. R. Costantino, P.-A. Nguyen, and C. C. Hsu. The effect of operating and formulation variables on the morphology of spray-dried protein particles. Pharm. Dev. Technol. 2:213-223 (1997).

93. J. J. Nijdam and T. A. G. Langrish. An investigation of milk powders produced by a laboratory-scale spray dryer. Dry. Technol. 23:1043-1056 (2005).

94. F. J. Wang, and C.-H. Wang. Effects of fabrication conditions on the characteristics of etanidazole spray-dried microspheres. J. Microencapsul. 19:495-510 (2002).

95. S. El Golli, J. Bricard, P.-Y. Turpin, and C. Treiner. The evaporation of saline droplets. J. Aerosol Sci. 5:273-292 (1974).

96. K. Alexander and C. J. King. Factors governing surface morphology of spray-dried amorphous substances. Dry. Technol. 3:321-348 (1985).

97. C. G. Greenwald and C. J. King. The mechanism of particle expansion in spray drying of foods. Food Process Eng. 78:101110 (1982).

98. D. A. Wallack, T. M. El-Sayed, and C. J. King. Changes in particle morphology during drying of drops of carbohydrate solutions and food liquids. 2. Effects on drying rate. Ind. Eng. Chem. Res. 29:2354-2357 (1990).

99. K. Anders, N. Roth, and A. Frohn. Operation characteristics of vibrating-orifice generators: the coherence length. Part. Part. Syst. Charact. 9:40-43 (1992).

100. R. Vehring and G. Schweiger. Raman scattering on liquid aerosol particles: concentration measurements on droplet chains. J. Aerosol Sci. 22:S399-S402 (1991).

101. V. Devarakonda, and A. K. Ray. Effect of inter-particle interactions on evaporation of droplets in a linear array. J. Aerosol Sci. 34:837-857 (2003).

102. B. Adhikari, T. Howes, B. R. Bhandari, and V. Truong. Experimental studies and kinetics of single drop drying and their relevance in drying of sugar-rich foods: a review. Int. J. Food Prop. 3:323-351 (2000).

103. K. Mosén, K. Bäckström, K. Thalberg, T. Schaefer, H. G. Kristensen, and A. Axelsson. Particle formation and capture during spray drying of inhalable particles. Pharm. Dev. Technol. 9:409-417 (2004).

104. J. E. Elversson, A. Millqvist-Fureby, G. Alderborn, and U. Elofsson. Droplet and particle size relationship and shell thickness of inhalable lactose particles during spray drying. J. Pharm. Sci. 92:900-910 (2003).

105. J. Elversson, K. Andersson, and A. Millqvist-Fureby. An atomic force microscopy approach for assessment of particle density applied to single spray-dried carbohydrate particles. J. Pharm. Sci. 96:905-912 (2007)

106. M. Maury, K. Murphy, S. Kumar, A. Maurer, and G. Lee. Spray-drying of proteins: effects of sorbitol and trehalose on aggregation and FT-IR amide I spectrum of an immunoglobulin G. Eur. J. Pharm. Biopharm. 59:251-261 (2005).

107. N. Y. K. Chew and H.-K. Chan. Use of solid corrugated particles to enhance powder performance. Pharm. Res. 18:1570-1577 (2001).

108. Y.-F. Maa, P.-A. T. Nguyen, and S. W. Hsu. Spray-drying of airliquid interface sensitive recombinant human growth hormone. J. Pharm. Sci. 87:152-159 (1998).

109. M. Ameri and Y.-F. Maa. Spray drying of biopharmaceuticals: stability and process considerations. Dry. Technol. 24:763-768 (2006).

110. K. Samborska, D. Witrowa-Rajchert, and A. Gonçalves. Spraydrying of alpha-amylase - the effect of process variables on the enzyme inactivation. Dry. Technol. 23:941-953 (2005).

111. G. S. Zijlstra, W. L. J. Hinrichs, A. H. de Boer, and H. W. Frijlink. The role of particle engineering in relation to formulation and de-agglomeration principle in the development of a dry powder formulation for inhalation of cetrorelix. Eur. J. Pharm. Sci. 23:139-149 (2004).

112. K. Ståhl, M. Claesson, P. Lilliehorn, H. Lindén, and K. Bäckström. The effect of process variables on the degradation and physical properties of spray dried insulin intended for inhalation. Int. J. Pharm. 233:227-237 (2002).

113. T.-Y. Ting, I. Gonda, and E. M. Gipps. Microparticles of polyvinyl alcohol for nasal delivery. I. Generation by spraydrying and spray-desolvation. Pharm. Res. 9:1330-1335 (1992).

114. B. Baras, M.-A. Benoit, and J. Gillard. Parameters influencing the antigen release from spray-dried poly(DL-Lactide) microparticles. Int. J. Pharm. 200:133-145 (2000).

115. H.-Y. Li and J. Birchall. Chitosan-modified dry powder formulations for pulmonary gene delivery. Pharm. Res. 23:941-950 (2006).

116. H. Bernstein, J. A. Straub, H. T. Brush, and R. E. Wing. Microencapsulated Fluorinated Gases for Use as Imaging Agents, Acusphere, Inc. USA Patent 5,611,344, 1997.

117. L. Mu and S. S. Feng. Fabrication, characterization and in vitro release of paclitaxel (taxol) loaded poly (lactic-co-glycolic acid) microspheres prepared by spray drying technique with lipid/ cholesterol emulsifiers. J. Control. Release 76:239-254 (2001).

118. Y.-J. Fu, F.-L. Mi, T.-B. Wong, and S.-S. Shyu. Characteristic and controlled release of anticancer drug loaded poly (D,LLactide) microparticles prepared by spray drying technique. $J$. Microencapsul. 18:733-747 (2001).

119. K. Hadinoto, P. Phanapavudhikul, Z. Kewu, and R. B. H. Tan. Dry powder aerosol delivery of large hollow nanoparticulate aggregates as prospective carriers of nanoparticulate drugs: effects of phospholipids. Int. J. Pharm. 333:187-198 (2007).

120. R. E. Sievers, E. T. S. Huang, J. A. Villa, J. K. Kawamoto, M. M. Evans, and P. R. Brauer. Low-temperature manufacturing of fine pharmaceutical powders with supercritical fluid aerosolization in a bubble dryer ${ }^{\circledR}$. Pure Appl. Chem. 73:1299-1303 (2001).

121. R. E. Sievers, E. T. S. Huang, J. A. Villa, G. Engling, and P. R. Brauer. Micronization of water-soluble or alcohol-soluble pharmaceuticals and model compounds with a low temperature bubble dryer ${ }^{\circledR}$. J. Supercrit. Fluids 26:9-16 (2003).

122. P. Fäldt and B. Bergenståhl. The surface composition of spraydried protein-lactose powders. Colloids Surf., A Physicochem. Eng. Asp. 90:183-190 (1994).

123. M. Adler, M. Unger, and G. Lee. Surface composition of spraydried particles of bovine serum albumin / trehalose / surfactant Pharm. Res. 17:863-870 (2000).

124. J. Elversson. Spray-dried Powders for Inhalation, doctoral dissertation, Faculty of Pharmacy, Uppsala Universitet, Uppsala, 2005.

125. M. Adler and G. Lee. Stability and surface activity of lactate dehydrogenase in spray-dried trehalose. J. Pharm. Sci. 88:199208 (1999).

126. K. Landström, B. Bergenståhl, J. Alsins, and M. Almgren. A fluorescence method for quantitative measurements of specific protein at powder surfaces. Colloids Surf., B Biointerfaces 12:429-440 (1999).

127. K. Landström, J. Alsins, and B. Bergenståhl. Competitive protein adsorption between bovine serum albumin and $\beta$-lactoglobulin during spray-drying. Food Hydrocoll. 14:75-82 (2000).

128. K. Landström, T. Arnebrant, J. Alsins, and B. Bergenståhl. Competitive protein adsorption between $\beta$-casein and $\beta$ lactoglobulin during spray-drying: effect of calcium induced association. Food Hydrocoll. 17:103-116 (2003).

129. G. P. Pedersen, P. Fäldt, B. Bergenståhl, and H. G. Kristensen. Solid state characterisation of a dry emulsion: a potential drug delivery system. Int. J. Pharm. 171:257-270 (1998).

130. A. Columbano, G. Buckton, and P. Wikeley. Characterisation of surface modified salbutamol sulphate-alkylpolyglycoside microparticles prepared by spray drying. Int. J. Pharm. 253:61-70 (2003).

131. A. Millqvist-Fureby, M. Malmsten, and B. Bergenståhl. Spraydrying of trypsin - surface characterisation and activity preservation. Int. J. Pharm. 188:243-253 (1999).

132. J. Elversson and A. Millqvist-Fureby. In situ coating-an approach for particle modification and encapsulation of proteins during spray-drying. Int. J. Pharm 323:52-63 (2006). 
133. J. J. Nijdam and T. A. G. Langrish. The effect of surface composition on the functional properties of milk powders. $J$. Food Eng. 77:919-925 (2006).

134. P. Fäldt, B. Bergenståhl, and G. Carlsson. The surface coverage of fat on food powders analyzed by ESCA (Electron Spectroscopy for Chemical Analysis). Food Struct. 12:225-234 (1993).

135. E. H.-J. Kim, X. D. Chen, and D. Pearce. Surface characterization of four industrial spray-dried dairy powders in relation to chemical composition, structure and wetting property. Colloids Surf., B Biointerfaces 26:197-212 (2002).

136. D. Lechuga-Ballesteros, C. Charan, C. Stults, C. L. Stevenson, D. P. Miller, R. Vehring, V. Tep, and M.-C. Kuo. Trileucine improves dispersibility, aerosol performance and stability of spray-dried powders for inhalation. J. Pharm. Sci. (in press, 2007). DOI 10.1002/jps.21078.

137. N. Y. K. Chew and H.-K. Chan. The role of particle properties in pharmaceutical powder inhalation formulations. J. Aerosol Med. 15:325-330 (2002).

138. N. Y. K. Chew, P. Tang, H.-K. Chan, and J. A. Raper. How much particle surface corrugation is sufficient to improve aerosol performance of powders?. Pharm. Res. 22:148-152 (2005).

139. D. A. Head. Modeling the elastic deformation of polymer crusts formed by sessile droplet evaporation. Phys. Rev. E. 74:021601 (2006).

140. M. F. Hsu, M. G. Nikolaides, A. D. Dinsmore, A. R. Bausch, V. D. Gordon, X. Chen, J. W. Hutchinson, D. A. Weitz, and M. Marquez. Self-assembled shells composed of colloidal particles: fabrication and characterization. Langmuir 21:2963-2970 (2005).

141. D. A. Edwards, J. Hanes, G. Caponetti, J. Hrkach, A. BenJebria, M. L. Eskew, J. Mintzes, D. Deaver, N. Lotan, and R. Langer. Large porous particles for pulmonary drug delivery. Science 276:1868-1871 (1997).

142. R. Vanbever, J. D. Mintzes, J. Wang, J. Nice, D. Chen, R. Batycky, R. Langer, and D. A. Edwards. Formulation and physical characterization of large porous particles for inhalation. Pharm. Res. 16:1735-1742 (1999).

143. R. Vanbever, A. Ben-Jebria, J. D. Mintzes, R. Langer, and D. A. Edwards. Sustained release of insulin from insoluble inhaled particles. Drug Dev. Res. 48:178-185 (1999).

144. A. Ben-Jebria, D. Chen, M. L. Eskew, R. Vanbever, R. Langer and D. A. Edwards. Large porous particles for sustained protection from carbachol-induced bronchoconstriction in guinea pigs. Pharm. Res. 16:555-561 (1999).

145. A. Ben-Jebria, M. L. Eskew, and D. A. Edwards. Inhalation system for pulmonary aerosol drug delivery in rodents using large porous particles. Aerosol. Sci. Tech. 32:421-433 (2000).

146. J. Wang, A. Ben-Jebria, and D. A. Edwards. Inhalation of estradiol for sustained systemic delivery. J. Aerosol Med. 12:2736 (1999).

147. C. Bosquillon, P. G. Rouxhet, F. Ahimou, D. Simon, C. Culot, V. Préat, and R. Vanbever. Aerosolization properties, surface composition and physical state of spray-dried protein powders. J. Control. Release 99:357-367 (2004).

148. N. Tsapis, D. Bennett, K. O'Driscoll, K. Shea, M. M. Lipp, K. Fu, R. W. Clarke, D. Deaver, D. Yamins, J. Wright, C. A. Peloquin, D. A. Weitz, and D. A. Edwards. Direct lung delivery of para-aminosalicylic acid by aerosol particles. Tuberculosis 83:379-385 (2003)

149. C. Bosquillon, C. Lombry, V. Préat, and R. Vanbever. Influence of formulation excipients and physical characteristics of inhalation dry powders on their aerosolization performance. $J$. Control. Release 70:329-339 (2001).

150. N. Osborne, A. D. Sutton, and R. A. Johnson. Preparation of Hollow Microcapsules by Spray-drying an Aqueous Solution of a Wall-forming Material and a Water-miscible Solvent, Andaris Ltd. USA Patent 5,741,478, 1998.

151. U. Conte, P. Giunchedi, L. Maggi, and M. L. Torre. Spray dried albumin microspheres containing nicardipine. Eur. J. Pharm. Biopharm. 40:203-208 (1994).

152. A. D. Sutton and R. A. Johnson. Preparation of Further Diagnostic Agents, Quadrant Healthcare Ltd. USA Patent 6,015,546, 2000.

153. C. Bosquillon, V. Préat, and R. Vanbever. Pulmonary delivery of growth hormone using dry powders and visualization of its local fate in rats. J. Control. Release 96:233-244 (2004).
154. C. Dunbar, G. Scheuch, K. Sommerer, M. DeLong, A. Verma, and R. Batycky. In vitro and in vivo dose delivery characteristics of large porous particles for inhalation. Int. J. Pharm. 245:179-189 (2002).

155. V. Codrons, F. Vanderbist, R. K. Verbeek, M. Arras, D. Lison, V. Preat, and R. Vanbever. Systemic delivery of parathyroid hormone (1-34) using inhalation dry powders in rats. J. Pharm. Sci. 92:938-950 (2003).

156. D. A. Edwards, A. Ben-Jebria, and R. Langer. Recent advances in pulmonary drug delivery using large, porous inhaled particles. J. Appl. Physiol. 85:379-385 (1998).

157. D. S. Kohane, N. Plesnila, S. S. Thomas, D. Le, R. Langer, and M. A. Moskowitz. Lipid-sugar particles for intracranial drug delivery: safety and biocompatibility. Brain Res. 946:206-213 (2002).

158. G. Colombo, R. Langer, and D. S. Kohane. Effect of excipient composition on the biocompatibility of bupivacaine-containing microparticles at the sciatic nerve. J. Biomed. Mater. Res. A 86:651-659 (2004).

159. D. S. Kohane, M. Lipp, R. C. Kinney, N. Lotan, and R. Langer. Sciatic nerve blockade with lipid-protein-sugar particles containing bupivacaine. Pharm. Res. 17:1243-1249 (2000).

160. D. S. Kohane, G. L. Holmes, Y. Chau, D. Zurakowski, R. Langer, and B. H. Cha. Effectiveness of muscimol-containing microparticles against pilocarpine-induced focal seizures. Epilepsia 43:1462-1468 (2002).

161. D. S. Kohane, M. Lipp, R. C. Kinney, D. C. Anthony, D. N. Louis, N. Lotan, and R. Langer. Biocompatibility of lipidprotein-sugar particles containing bupivacaine in the epineurium. J. Biomed. Mater. Res. 59:450-459 (2001).

162. G. Colombo, R. Padera, R. Langer, and D. S. Kohane Prolonged duration local anesthesia with lipid-protein-sugar particles containing bupivacaine and dexamethasone. $J$. Biomed. Mater. Res. 75A:458-464 (2005).

163. D. S. Kohane, S. E. Smith, D. N. Louis, G. Colombo, P. Ghoroghchian, N. G. M. Hunfeld, C. B. Berde, and R. Langer. Prolonged duration local anesthesia from tetrodotoxin-enhanced local anesthetic microspheres. Pain 104:415-421 (2003).

164. M. DeLong, J. Wright, M. Dawson, T. Meyer, K. Sommerer and C. Dunbar. Dose delivery characteristics of the AIR ${ }^{\circledR}$ pulmonary delivery system over a range of inspiratory flow rates. J. Aerosol Med. 18:452-459 (2005).

165. D. Edwards, C. Conlon, S. Dreesen, and M. DeLong. Inhalation Device and Method, Advanced Inhalation Research, Inc. USA Patent 6,732,732, 2004.

166. D. B. Muchmore, B. Silverman, A. De la Peña, and J. Tobian. The AIR $^{\circledR}$ inhaled insulin system: system components and pharmacokinetic/glucodynamic data. Diabetes Technol. Ther. 9: S41-S47 (2007).

167. K. M. Rave, L. Nosek, A. De La Peña, M. Seger, C. S. Ernest, L. Heineman, R. P. Batycky, and D. B. Muchmore. Dose response of inhaled dry-powder insulin and dose equivalence to subcutaneous insulin lispro. Diabetes Care 28:2400-2405 (2005).

168. S. L. Ellis, K. A. Gemperline, and S. K. Garg. Review of phase 2 studies utilizing the AIR ${ }^{\circledR}$ particle technology in the delivery of human insulin inhalation powder versus subcutaneous regular or lispro insulin in subjects with type 1 or type 2 diabetes. Diabetes Technol. Ther. 9:S48-S56 (2007).

169. S. Garg, J. Rosenstock, B. L. Silverman, B. Sun, C. S. Konkoy, A. De La Peña, and D. B. Muchmore. Efficacy and safety of preprandial human insulin inhalation powder versus injectable insulin in patients with type 1 diabetes. Diabetologia 49:891-899 (2006).

170. V. Codrons, F. Vanderbist, B. Ucakar, V. Preat, and R. Vanbever. Impact of formulation and methods of pulmonary delivery on absorption of parathyroid hormone (1-34) from rat lungs. J. Pharm. Sci. 93:1241-1252 (2004).

171. Y. Qi, G. Zhao, D. Liu, Z. Shriver, M. Sundaram, S. Sengupta, G. Venkataraman, R. Langer, and R. Sasisekharam. Delivery of therapeutic levels of heparin and low-molecular-weight heparin through a pulmonary route. Proc. Natl. Acad. Sci. USA 101:9867-9872 (2004).

172. R. T. Bartus, D. Emerich, P. Snodgrass-Belt, K. Fu, H. SalzbergBrenhouse, D. Lafreniere, L. Novak, E.-S. Lo, T. Cooper, and 
A. S. Basile. A pulmonary formulation of 1-dopa enhances its effectiveness in a rat model of Parkinson's disease. J. Pharmacol. Exp. Ther. 310:828-835 (2004).

173. L. A. Dellamary, T. E. Tarara, D. J. Smith, C. H. Woelk, A. Adractas, M. L. Costello, H. Gill, and J. G. Weers. Hollow porous particles in metered dose inhalers. Pharm. Res. 17:168-174 (2000).

174. J. Weers. Dispersible powders for inhalation applications. Innov. Pharm. Technol. 1:111-116 (2000).

175. T. Tarara, J. Weers, and L. Dellamary. Engineered powders for inhalation. Respir. Drug Deliv. Proc. VII:413-416 (2000).

176. C. Vega and Y. H. Roos. Invited review: spray-dried dairy and dairy-like emulsions-compositional considerations. J. Dairy Sci. 89:383-401 (2006).

177. T. E. Tarara, J. G. Weers, A. Kabalnov, E. G. Schutt, and L. A. Dellamary. Methods of Spray Drying Pharmaceutical Compositions, Inhale Therapeutic Systems USA Patent 6,565,885, 2003.

178. M. T. Newhouse, P. H. Hirst, S. P. Duddu, Y. H. Walter, T. E. Tarara, A. R. Clark, and J. G. Weers. Inhalation of a dry powder tobramycin pulmosphere formulation in healthy volunteers. Chest 124:360-366 (2003).

179. P. H. Hirst, G. R. Pitcairn, J. G. Weers, T. E. Tarara, A. R. Clark, L. A. Dellamary, G. Hall, J. Shorr, and S. P. Newman. In vivo lung deposition of hollow porous particles from a pressurized metered dose inhaler. Pharm. Res. 19:258-264 (2002).

180. S. P. Duddu, S. A. Sisk, Y. A. Walter, T. E. Tarara, K. E. Trimble, A. R. Clark, M. A. Eldon, R. C. Elton, M. Pickford, P. H. Hirst, S. P. Newman, and J. G. Weers. Improved lung delivery from a passive dry powder inhaler using an engineered pulmosphere powder. Pharm. Res. 9:689-695 (2002).

181. T. E. Tarara, M. S. Hartman, H. Gill, A. A. Kennedy, and J. G. Weers. Characterization of suspension-based metered dose inhaler formulations composed of spray-dried budesonide microcrystals dispersed in HFA-134a. Pharm. Res. 21:1607-1614 (2004).

182. J. D. Andya, Y.-F. Maa, H. R. Costantino, P.-A. Nguyen, N. Dasovich, T. D. Sweeney, C. C. Hsu, and S. J. Shire. The effect of formulation excipients on protein stability and aerosol performance of spray-dried powders of a recombinant humanized anti-IgE monoclonal antibody. Pharm. Res. 16:350-358 (1999).

183. A. I. Bot, D. J. Smith, S. Bot, L. Dellamary, T. E. Tarara, S. Harders, W. Phillips, J. G. Weers, and C. M. Woods. Receptormediated targeting of spray-dried lipid particles coformulated with immunoglobulin and loaded with a prototype vaccine. Pharm. Res. 18:971-979 (2001).

184. J. Weers, T. Tarara, R. Malcolmson, and D. Leung. Embedded crystals in low density particles: formulation, manufacture, and properties. Respir. Drug Deliv. Proc. X:297-306 (2006)

185. G. Pilcer, T. Sebti, and K. Amighi. Formulation and characterization of lipid-coated tobramycin particles for dry powder inhalation. Pharm. Res. 23:931-940 (2006).

186. L. A. Trevino, E. G. Schutt, D. H. Klein, T. E. Tarara, J. G. Weers, and A. Kabalnov. Stabilized Gas Emulsion Containing Phospholipid for Ultrasound Contrast Enhancement, Alliance Pharmaceutical Corp. USA Patent 5,798,091, 1998.

187. D. J. Smith, L. M. Gambone, T. Tarara, D. R. Meays, L. A. Dellamary, C. M. Woods, and J. Weers. Liquid dose pulmonary instillation of gentamicin pulmospheres formulations: tissue distribution and pharmacokinetics in rabbits. Pharm. Res. 18:1556-1561 (2001).

188. E. W. Dickson, S. O. Heard, T. E. Tarara, J. G. Weers, A. B. Brueggemann, and G. V. Doern. Liquid ventilation with perflubron in the treatment of rats with pneumococcal pneumonia. Crit. Care Med. 30:393-395 (2002).

189. E. W. Dickson, G. V. Doern, L. Trevino, M. Mazzoni, and S. O. Heard. Prevention of descending pneumonia in rats with perflubron-delivered tobramycin. Acad. Emerg. Med. 10:10191023 (2003).

190. A. Bot, D. Smith, T. Tarara, S. Harders, S. Bot, I. Langsetmo, C. Woods, and J. Weers. Vaccination by antigen delivery to airway antigen presenting cells via engineered, lipid-based microparticles. Respir. Drug Deliv. Proc. VII:327-328 (2000)

191. D. J. Smith, S. Bot, L. Dellamary, and A. Bot. Evaluation of novel aerosol formulations designed for mucosal vaccination against influenza virus. Vaccine 21:2805-2812 (2003).

192. A. I. Bot, T. E. Tarara, D. J. Smith, S. R. Bot, C. M. Woods, and J. G. Weers. Novel lipid-based hollow-porous microparticles as a platform for immunoglobulin delivery to the respiratory tract. Pharm. Res. 17:275-283 (2000).

193. L. Dellamary, D. J. Smith, A. Bloom, S. Bot, G.-R. Guo, H Deshmuk, M. Costello, and A. Bot. Rational design of solid aerosols for immunoglobulin delivery by modulation of aerodynamic and release characteristics. J. Control. Release 95:489500 (2004).

194. J. G. Weers, T. E. Tarara, H. Gill, B. S. English, and L. A. Dellamary. Homodispersion technology for HFA suspensions: particle engineering to reduce dosing variance. Respir. Drug Deliv. Proc. VII:91-97 (2000).

195. P. Rogueda. Novel hydrofluoroalkane suspension formulations for respiratory drug delivery. Expert Opin. Drug Deliv. 2:625638 (2005)

196. H. Steckel and H. G. Brandes. A novel spray-drying technique to produce low density particles for pulmonary delivery. Int. $J$. Pharm. 278:187-195 (2004).

197. J. A. Straub, E. Mathiowitz, H. Bernstein, H. T. Brush, and R. E. Wing. Method for Making Porous Microparticles by Spray Drying, Acusphere Inc. USA Patent 5,853,698, 1998.

198. J. Straub, H. Bernstein, D. E. Chickering, S. Khattak, and G. Randall. Porous Drug Matrices and Methods Of Manufacture Thereof, Acusphere, Inc. USA Patent 6,395,300, 2002.

199. P. Narayan, D. Marchant, and M. A. Wheatley. Optimization of spray drying by factorial design for production of hollow microspheres for ultrasound imaging. J. Biomed. Mater. Res. 56:333-341 (2001)

200. J. Straub, H. Bernstein, D. E. Chickering, and G. Randall. Porous Celecoxib Matrices and Methods of Manufacture Thereof, Acusphere, Inc. USA Patent 6,589,557, 2003.

201. M. A. Wheatley and P. J. Narayan. Hollow Polymer Microcapsules and Method of Producing the Same, Drexel University, USA Patent 5,955,143, 1999.

202. C. Gervelas, A.-L. Serandour, S. Geiger, G. Grillon, P. Fritsch, C. Taulelle, B. Le Gall, H. Benech, J.-R. Deverre, E. Fattal, and N. Tsapis. Direct lung delivery of a dry powder formulation of DTPA with Improved aerosolization properties: effect on lung and systemic decorporation of plutonium. J. Control. Release 118:78-86 (2007)

203. J. A. Straub, D. E. Chickering, C. C. Church, B. Shah, T. Hanlon, and H. Bernstein. Porous PLGA microparticles: AI-700, an intravenously administered ultrasound contrast agent for use in echocardiography. J. Control. Release 108:21-32 (2005).

204. J. A. Straub, D. E. Chickering, J. C. Lovely, J. C. Zhang, H. Zhang, B. Shah, W. R. Waud, and H. Bernstein. Intravenous hydrophobic drug delivery: a porous particle formulation of paclitaxel (AI-850). Pharm. Res. 22:347-355 (2005).

205. A. Madene, M. Jacquot, J. Scher, and S. Desobry. Flavour encapsulation and controlled release-a review. Int. J. Food Sci. Technol. 41:1-21 (2006).

206. K. G. H. Desai and H. J. Park. Recent developments in microencapsulation of food ingredients. Dry. Technol. 23:13611394 (2005).

207. B. F. Gibbs, S. Kermasha, I. Alli, and C. N. Mulligan Encapsulation in the food industry: a review. Int. J. Food Sci. Nutr. 50:213-224 (1999).

208. M. Sakagami, K. Sakon, W. Kinoshita, and Y. Makino. Enhanced pulmonary absorption following aerosol administration of mucoadhesive powder microspheres. J. Control. Release 77:117-129 (2001).

209. C. Hasçiçek, N. Gönül, and N. Erk. Mucoadhesive microspheres containing gentamicin sulfate for nasal administration: preparation and in vitro characterization. Il Farmaco 58:11-16 (2003).

210. M. Sakagami, W. Kinoshita, K. Sakon, J.-I. Sato, and Y. Makino. Mucoadhesive beclomethasone microspheres for powder inhalation: their pharmacokinetics and pharmacodynamics evaluation. J. Control. Release 80:207-218 (2002).

211. F. Cilurzo, F. Selmin, P. Minghetti, I. Rimoldi, F. Demartin, and L. Montanari. Fast-dissolving mucoadhesive microparticulate delivery system containing piroxicam. Eur. J. Pharm. Sci. 24:355-361 (2005)

212. M. L. Bruschi, M. L. C. Cardoso, M. B. Lucchesi, and M. P. D. Gremião. Gelatin microparticles containing propolis obtained by spray-drying technique: preparation and characterization. Int. J. Pharm. 264:45-55 (2003). 
213. S. Zgoulli, V. Grek, G. Barre, G. Goffinet, P. Thonart, and S Zinner. Microencapsulation of erythromycin and clarithromycin using a spray-drying technique. J. Microencapsul. 16:565-571 (1999).

214. T. G. Park, M. J. Alonso, and R. Langer. Controlled release of proteins from poly(L-lactic acid) coated polyisobutylcyanoacrylate microcapsules. J. Appl. Polym. Sci. 52:1797-1807 (1994).

215. P. He, S. S. Davis, and L. Illum. Sustained release chitosan microspheres prepared by novel spray drying methods. $J$. Microencapsul. 16:343-355 (1999).

216. A. Martinac, J. Filipović-Gričić, B. Perissutti, D. Voinovich, and Ž. Pavelić. Spray-dried chitosan/ethylcellulose microspheres for nasal drug delivery: swelling study and evaluation of in vitro drug release properties. J. Microencapsul. 22:549-561 (2005).

217. V. Lemaire, J. Bélair, and P. Hildgen. Structural modeling of drug release from biodegradable porous matrices based on a combined diffusion/erosion process. Int. J. Pharm. 258:95-107 (2003).

218. B. Baras, M.-A. Benoit, O. Poulain-Godefroy, A.-M. Schacht, A. Capron, J. Gillard, and G. Riveau. Vaccine properties of antigens entrapped in microparticles produced by spray-drying technique and using various polyester polymers. Vaccine. 18:1495-1505 (2000).

219. B.-B. C. Youan. Microencapsulation of superoxide dismutase into biodegradable microparticles by spray-drying. Drug Deliv. 11:209-214 (2004).

220. S. Prior, C. Gamazo, J. M. Irache, H. P. Merkle, and B. Gander Gentamicin encapsulation in PLA:PLGA microspheres in view of treating brucella infections. Int. J. Pharm. 196:115-125 (2000).

221. M. K. Taylor, A. J. Hickey, and M. VanOort. Manufacture, characterization, and pharmacodynamic evaluation of engineered ipratropium bromide particles. Pharm. Dev. Technol. 11:321-336 (2006).

222. B. Gander, E. Wehrli, R. Alder, and H. P. Merkle. Quality improvement of spray-dried, protein-loaded D,L-PLA microspheres by appropriate polymer solvent selection. J. Microencapsul. 12:83-97 (1995).

223. G. Boehm, M. Peyre, D. Sesardic, R. J. Huskisson, F. Mawas, A. Douglas, D. Xing, H. P. Merkle, B. Gander, and P. Johansen. On technological and immunological benefits of multivalent singleinjection microsphere vaccines. Pharm. Res. 19:1330-1336 (2002).

224. F.-J. Wang and C.-H. Wang. Etanidazole-loaded microspheres fabricated by spray-drying different poly(lactide/glycolide) polymers: effects on microsphere properties. J. Biomater. Sci. Polymer Ed. 14:157-183 (2003).

225. B. Baras, M.-A. Benoit, and J. Gillard. Influence of various technological parameters on the preparation of spray-dried poly (epsilon-caprolactone) microparticles containing a model antigen. J. Microencapsul. 17:485-498 (2000).

226. M. D. Blanco, M. V. Bernardo, R. L. Sastre, R. Olmo, E. Muñiz, and J. M. Teijón. Preparation of bupivacaine-loaded poly (epsilon-caprolactone) microspheres by spray drying: drug release studies and biocompatibility. Eur. J. Pharm. Biopharm. 55:229-236 (2003)

227. M. Murillo, C. Gamazo, M. M. Goñi, J. M. Irache, and M. J. Blanco-Príeto. Development of microparticles prepared by spray-drying as a vaccine delivery system against brucellosis. Int. J. Pharm. 242:341-344 (2002).

228. R. L. Sastre, M. D. Blanco, C. Teijón, R. Olmo, and J. M. Teijón. Preparation and characterization of 5-fluorouracilloaded poly ( $\varepsilon$-caprolactone) microspheres for drug administration. Drug Dev. Res. 63:41-53 (2004).

229. S. Harikarnpakdee, V. Lipipun, N. Sutanthavibul, and G. C. Ritthidej. Spray dried mucoadhesive microspheres: preparation and transport through nasal cell monolayer. AAPS PharmSciTech 7:E1-E10 (2006).

230. E. Esposito, F. Cervellati, E. Menegatti, C. Nastruzzi, and R. Cortesi. Spray dried eudragit microparticles as encapsulation devices for vitamin C. Int. J. Pharm. 242:329-334 (2002).

231. D. S. Kohane, D. G. Anderson, C. Yu, and R. Langer. pHtriggered release of macromolecules from spray-dried polymethacrylate microparticles. Pharm. Res. 20:1533-1538 (2003).

232. T. T. Thomas, D. S. Kohane, A. Wang, and R. Langer. Microparticulate formulations for the controlled release of interleukin-2. J. Pharm. Sci. 93:1100-1109 (2004).
233. E. Esposito, R. Roncarati, R. Cortesi, F. Cervellati, and C. Nastruzzi. Production of eudragit microparticles by spraydrying technique: influence of experimental parameters on morphological and dimensional characteristics. Pharm. Dev. Technol. 5:267-278 (2000).

234. R. Cortesi, C. Mischiati, M. Borgatti, L. Breda, A. Romanelli, M. Saviano, C. Pedone, R. Gambari, and C. Nastruzzi. Formulations for natural and peptide nucleic acids based on cationic polymeric submicron particles. AAPS PharmSci. 6:1-12 (2003).

235. N. Hegazy, M. Demirel, and Y. Yazan. Preparation and in vitro evaluation of pyridostigmine bromide microparticles. Int. J. Pharm. 242:171-174 (2002).

236. W. N. Haining, D. G. Anderson, S. R. Little, M. S. von BerweltBaildon, A. A. Cardoso, P. Alves, K. Kosmatopoulos, L. M. Nadler, R. Langer, and D. S. Kohane. pH-triggered microparticles for peptide vaccination. J. Immunol. 173:2578-2585 (2004).

237. G. F. Palmieri, G. Bonacucina, P. Di Martino, and S. Martelli. Gastroresistant microspheres containing ketoprofen. J. Microencapsul. 19:111-119 (2002)

238. C. Muzzarelli, V. Stanic, L. Gobbi, G. Tosi, and R. A. A Muzzarelli. Spray-drying of solutions containing chitosan together with polyuronans and characterisation of the microspheres. Carbohydr. Polym. 57:73-82 (2004).

239. Y.-C. Huang, M.-K. Yeh, S.-N. Cheng, and C.-H. Chiang. The characteristics of betamethasone-loaded chitosan microparticles by spray-drying method. J. Microencapsul. 20:459-472 (2003).

240. P. He, S. S. Davis, and L. Illum. Chitosan microspheres prepared by spray drying. Int. J. Pharm. 187:53-65 (1999).

241. J. Filipović-Gričić, D. Voinovich, M. Moneghini, M. BećirevićLaćan, L. Magarotto, and I. Jalšenjak. Chitosan microspheres with hydrocortisone and hydrocortisone-hydroxypropyl- $\beta$-cyclodextrin inclusion complex. Eur. J. Pharm. Sci. 9:373-379 (2000).

242. F.-L. Mi, Y.-C. Tan, H.-F. Liang, and H.-W. Sung. In vivo biocompatibility and degradability of a novel injectablechitosan-based implant. Biomaterials 23:181-191 (2002).

243. A. Martinac, J. Filipović-Gričić, M. Barbarić, B. Zorc, D Voinovich, and I. Jalšenjak. Gemfibrozil encapsulation and release from microspheres and macromolecular conjugates. Eur. J. Pharm. Sci. 17:207-216 (2002).

244. P. Giunchedi, C. Juliano, E. Gavini, M. Cossu, and M. Sorrenti. Formulation and in vivo evaluation of chlorhexidine buccal tablets prepared using drug-loaded chitosan microspheres. Eur. J. Pharm. Biopharm. 53:233-239 (2002).

245. J. Filipović-Gričić, B. Perissutti, M. Moneghini, D. Voinovich, A. Martinac, and I. Jalšenjak. Spray-dried carbamazepineloaded chitosan and HPMC microspheres: preparation and characterisation. J. Pharm. Pharmacol. 55:921-931 (2003).

246. Y. C. Huang, A. Vieira, M. K. Yeh, and C. H. Chiang. Pulmonary anti-inflammatory effects of chitosan microparticles containing betamethasone. J. Bioact. Compat. Polym. 22:30-41 (2007).

247. Y. C. Huang and M. K. Yeh. Formulation factors in preparing BTM-chitosan microspheres by spray drying method. Int. J. Pharm. 242:239-242 (2002).

248. B. F. Oliveira, M. H. A. Santana, and M. I. Ré. Spray-dried chitosan microspheres cross-linked with D, L-glyceraldehyde as a potential drug delivery system: preparation and characterization. Braz. J. Chem. Eng. 22:353-360 (2005).

249. H. O. Alpar, S. Somavarapu, K. N. Atuah, and V. W. Bramwell. Biodegradable mucoadhesive particulates for nasal and pulmonary antigen and DNA delivery. Adv. Drug Deliv. Rev. 57:411430 (2005).

250. Y.-C. Huang, C.-H. Chiang, and M.-K. Yeh. Optimizing formulation factors in preparing chitosan microparticles by spray-drying method. J. Microencapsul. 20:247-260 (2003).

251. K. G. Desai, C. Liu, and H. J. Park. Characteristics of vitamin C encapsulated tripolyphosphate-chitosan microspheres as affected by chitosan molecular weight. J. Microencapsul. 23:79-90 (2006).

252. K. G. Desai, and H. J. Park. Effect of manufacturing parameters on the characteristics of vitamin $\mathrm{C}$ encapsulated 
tripolyphosphate-chitosan microspheres prepared by spraydrying. J. Microencapsul. 23:91-103 (2006).

253. K. G. H. Desai and H. J. Park. Encapsulation of vitamin C in tripolyphosphate cross-linked chitosan microspheres by spray drying. J. Microencapsul. 22:179-192 (2005).

254. H. Takahashi, R. Chen, H. Okamoto, and K. Danjo. Acetaminophen particle design using chitosan and a spray-drying technique. Chem. Pharm. Bull. 53:37-41 (2005).

255. M. Asada, H. Takahashi, H. Okamoto, H. Tanino, and K. Danjo. Theophylline particle design using chitosan by the spray drying. Int. J. Pharm. 270:167-174 (2004).

256. J. Adamiec and Z. Modrzejewska. Some structural properties of spray-dried chitosan microgranules. Dry. Technol. 23:1601-1611 (2005).

257. C. Liu, K. G. H. Desai, X. Tang, and X. Chen. Drug release kinetics of spray-dried chitosan microspheres. Dry. Technol. 24:769-776 (2006).

258. N. Grattard, M. Pernin, B. Marty, G. Roudaut, D. Champion, and M. Le Meste. Study of release kinetics of small and high molecular weight substances dispersed into spray-dried ethylcellulose microspheres. J. Control. Release 84:125-135 (2002).

259. K. Surendrakumar, G. P. Martyn, E. C. M. Hodgers, M. Jansen, and J. A. Blair. Sustained release of insulin from sodium hyaluronate based dry powder formulations after pulmonary delivery to beagle dogs. J. Control. Release 91:385-394 (2003).

260. H. Nettey, D. Haswani, C. W. Oettinger, and M. D'Souza. Formulation and testing of vancomycin loaded albumin microspheres prepared by spray-drying. J. Microencapsul. 23:632-642 (2006).

261. P. Le Corre, J. P. Estèbe, R. Clément, L. Du Plessis, F. Chevanne, C. Ecoffey, and R. Le Verge. Spray-dryed bupivacaine-loaded microspheres: in vitro evaluation and biopharmaceutics of bupivacaine following brachial plexus administration in sheep. Int. J. Pharm. 238:191-203 (2002).

262. C.-S. Chaw, C.-W. Tan, Y.-Y. Yang, L. Wang, and S. M. Moochhala. Design of physostigmine-loaded polymeric microparticles for pretreatment against exposure to organophosphate agents. Biomaterials 24:1271-1277 (2003).

263. L. Montanari, F. Cilurzo, F. Selmin, B. Conti, I. Genta, G. Poletti, F. Orsini, and L. Valvo. Poly(lactide-co-glycolide) microspheres containing bupivacaine: comparison between gamma and beta irradiation effects. J. Control. Release 90:281-290 (2003).

264. S. Prior, B. Gander, C. Lecároz, J. M. Irache, and C. Gamazo. Gentamicin-loaded microspheres for reducing the intracellular brucella abortus load in infected monocytes. J. Antimicrob. Chemother. 53:981-988 (2004).

265. S. Prior, B. Gander, J. M. Irache, and C. Gamazo. Gentamicinloaded microspheres for treatment of experimental brucella abortus infection in mice. J. Antimicrob. Chemother. 55:1032$1036(2005)$

266. L. Wang, C.-S. Chaw, Y.-Y. Yang, S. M. Moochhala, B. Zhao, $\mathrm{S}$. $\mathrm{Ng}$, and J. Heller. Preparation, characterization, and in vitro evaluation of physostigmine-loaded poly(ortho ester) and poly (ortho ester)/poly(D,L-lactide-co-glycolide) blend microspheres fabricated by spray drying. Biomaterials 25:3275-3282 (2004).

267. P. O'Hara and A. J. Hickey. Respirable PLGA microspheres containing rifampicin for the treatment of tuberculosis: manufacture and characterization. Pharm. Res. 17:955-961 (2000)

268. P. A. Rivera, M. C. Martinez-Oharriz, M. Rubio, J. M. Irache, and S. Espuelas. Fluconazole encapsulation in PLGA microspheres by spray-drying. J. Microencapsul. 21:203-211 (2004).

269. S. Takada, Y. Uda, H. Toguchi, and Y. Ogawa. Application of a spray drying technique in the production of TRH-containing injectable sustained-release microparticles of biodegradable polymers. PDA J. Pharm. Sci. Technol. 49:180-184 (1995).

270. S. Santoyo, E. Ga de Jalón, P. Ygartua, M. J. Renedo, and M. J. Blanco-Príeto. Optimization of topical cidofovir penetration using microparticles. Int. J. Pharm. 242:107-113 (2002).

271. R. Lin, L. S. Ng, and C.-H. Wang. In vitro study of anticancer drug doxorubicin in PLGA-based microparticles. Biomaterials 26:4476-4485 (2005).

272. M. D. Blanco, R. L. Sastre, C. Teijón, R. Olmo, and J. M. Teijón. 5-Fluorouracil-loaded microspheres prepared by spraydrying poly(D,L-lactide) and poly(lactide-co-glycolide) poly- mers: characterization and drug release. J. Microencapsul. 22:671-682 (2005)

273. P. K. Naraharisetti, H. C. G. Lee, Y.-C. Fu, D.-J. Lee, and C.-H Wang. In vitro and in vivo release of gentamicin from biodegradable discs. J. Biomed. Mater. Res. B., Appl. Biomater 77:329-337 (2006)

274. F. Quaglia, G. De Rosa, E. Granata, F. Ungaro, and E. Fattal. Feeding liquid, non-ionic surfactant and cyclodextrin affect the properties of insulin-loaded poly(lactide-co-glycolide) microspheres prepared by spray-drying. J. Control. Release 86:267278 (2003).

275. P. A. Burke, L. A. Klumb, J. D. Herberger, P.-A. Nguyen, R. A. Harrell, and M. Zordich. Poly(lactide-co-glycolide) microsphere formulations of darbepoetin alfa: spray drying is an alternative to encapsulation by spray-freeze drying. Pharm. Res. 21:500506 (2004).

276. B. Bittner, M. Morlock, H. Koll, G. Winter, and T. Kissel Recombinant human erythropoietin (rhEPO) loaded poly(lactide-co-glycolide) microspheres: influence of the encapsulation technique and polymer purity on microsphere characteristics. Eur. J. Pharm. Biopharm. 45:295-305 (1998).

277. G. Schwach, N. Oudry, S. Delhomme, M. Lück, H. Lindner, and R. Gurny. Biodegradable microparticles for sustained release of a new GnRH antagonist-part I: screening commercial PLGA and formulation technologies. Eur. J. Pharm. Biopharm. 56:327-336 (2003).

278. P. Giunchedi, B. Conti, I. Genta, U. Conte, and G. Puglisi Emulsion spray-drying for the preparation of albumin-loaded PLGA microspheres. Drug Dev. Ind. Pharm. 27:745-750 (2001).

279. M. J. Blanco-Príeto, K. Besseghir, O. Zerbe, D. Andris, P. Orsolini, F. Heimgartner, H. P. Merkle, and B. Gander. In vitro and in vivo evaluation of a somatostatin analogue released from PLGA microspheres. J. Control. Release 67:19-28 (2000).

280. M. J. Blanco-Príeto, M. A. Campanero, K. Besseghir, F. Heimgartner, and B. Gander. Importance of single or blended polymer types for controlled in vitro release and plasma levels of a somatostatin analogue entrapped in PLA/ PLGA microspheres. J. Control. Release 96:437-448 (2004).

281. M. Peyre, D. Sesardic, H. P. Merkle, B. Gander, and P. Johansen. An experimental divalent vaccine based on biodegradable microspheres induces protective immunity against tetanus and diphtheria. J. Pharm. Sci. 92:957-966 (2003).

282. M. Peyre, R. Audran, F. Estevez, G. Corradin, B. Gander, D. Sesardic, and P. Johansen. Childhood and malaria vaccines combined in biodegradable microspheres produce immunity with synergistic interactions. J. Control. Release 99:345-355 (2004).

283. P. Johansen, Y. Men, R. Audran, G. Corradin, H. P. Merkle, and B. Gander. Improving stability and release kinetics of microencapsulated tetanus toxoid by co-encapsulation of additives. Pharm. Res. 15:1103-1110 (1998).

284. P. Johansen, L. Moon, H. Tamber, H. P. Merkle, B. Gander, and D. Sesardic. Immunogenicity of single-dose diphtheria vaccines based on PLA/PLGA microspheres in guinea pigs. Vaccine 18:209-215 (2000)

285. P. Johansen, H. P. Merkle, and B. Gander. Technological considerations related to the up-scaling of protein microencapsulation by spray-drying. J. Microencapsul. 50:413-417 (2000).

286. S. Jilek, H. Zurkaulen, J. Pavlovic, H. P. Merkle, and E. Walter. Transfection of a mouse dendritic cell line by plasmid DNAloaded PLGA microparticles in vitro. Eur. J. Pharm. Biopharm. 58:491-499 (2004)

287. S. Jilek, H. P. Merkle, and E. Walter. DNA-loaded biodegradable microparticles as vaccine delivery systems and their interaction with dendritic cells. Adv. Drug Deliv. Rev. 57:377390 (2005)

288. V. R. Sinha, A. K. Singla, S. Wadhawan, R. Kaushik, R. Kumria, K. Bansal, and S. Dhawan. Chitosan microspheres as a potential carrier for drugs. Int. J. Pharm. 274:1-33 (2004).

289. P. Johansen, Y. Men, H. P. Merkle, and B. Gander. Revisiting PLA/PLGA microspheres: an analysis of their potential in parenteral vaccination. Eur. J. Pharm. Biopharm. 50:129-146 (2000).

290. M. T. Liang, N. M. Davies, J. T. Blanchfield, and I. Toth Particulate systems as adjuvants and carriers for peptide and protein antigens. Curr. Drug Deliv. 3:379-388 (2006). 
291. J. H. Park, M. Ye, and K. Park. Biodegradable polymers for microencapsulation of drugs. Molecules 10:146-161 (2005).

292. V. R. Sinha and A. Trehan. Biodegradable microspheres for protein delivery. J. Control. Release 90:261-280 (2003).

293. M. D. Louey. Controlled release products for respiratory delivery. Am. Pharm. Rev. 7:82-87 (2004).

294. D. Lu and A. J. Hickey. Pulmonary vaccine delivery. Exp. Rev. Vaccines 6:213-226 (2007).

295. J. G. Hardy and T. S. Chadwick. Sustained release drug delivery to the lungs: an option for the future. Clin. Pharmacokinet. 39:1-4 (2000).

296. P. Begat, R. Price, H. Harris, D. A. V. Morton, and J. N. Staniforth. The Influence of force control agents on the cohesive-adhesive balance in dry powder inhaler formulations. KONA 23:109-121 (2005).

297. D. Ganderton, D. A. V. Morton, and P. Lucas. Powders, Vectura Ltd. USA Patent 6,989,155, 2006.

298. J. N. Staniforth. Powders Comprising Anti-adherent Materials for Use in Dry Powder Inhalers, Vectura, Ltd. USA Patent $6,475,523,2002$.

299. H.-Y. Li, P. C. Seville, I. J. Williamson, and J. C. Birchall. The use of amino acids to enhance the aerosolisation of spray-dried powders for pulmonary gene therapy. J. Gene Med. 7:343-353 (2005).

300. R. P. Batycky, M. M. Lipp, and R. W. Niven. Use of Simple Amino Acids to Form Porous Particles During Spray Drying, Advanced Inhalation Research, Inc. USA Patent 6,586,008, 2003.

301. P. Lucas, K. Anderson, U. J. Potter, and J. N. Staniforth. Enhancement of small particle size dry powder aerosol formulations using an ultra low density additive. Pharm. Res. 16:1643-1647 (1999).

302. A. R. Najafabadi, K. Gilani, M. Barghi, and M. Rafiee-Tehrani. The effect of vehicle on physical properties and aerosolisation behaviour of disodium cromoglycate microparticles spray dried alone or with 1-leucine. Int. J. Pharm. 285:97-108 (2004).

303. J. Gliński, G. Chavepeyer, and J.-K. Platten. Surface properties of aqueous solutions of 1-leucine. Biophys. Chemist. 84:99-103 (2000).

304. R. P. Batycky, G. Caponetti, M. Childs, E. Ehrich, K. Fu, J. S. Hrkach, W.-I. Li, M. M. Lipp, M.-L. Pan, and J. Summa. Inhalable Epinephrine, Advanced Inhalation Research, Inc. International Patent WO 2004/002551, 2004.

305. N. Y. K. Chew, B. Y. Shekunov, H. H. Y. Tong, A. H. L. Chow, C. Savage, J. Wu, and H.-K. Chan. Effect of amino acids on the dispersion of disodium cromoglycate powders. J. Pharm. Sci. 94:2289-2300 (2005).

306. B. Kumar Padhi, M. B. Chougule, and A. Misra. Optimization of formulation components and characterization of large respirable powders containing high therapeutic payload. Pharm. Dev. Technol. 11:465-475 (2006).

307. R. Vehring, D. Lechuga-Ballesteros, and D. P. Miller. Pharmaceutical Formulation Comprising a Water-insoluble Active Agent, Nektar Therapeutics International Patent WO 2005/000267, 2005.

308. N. R. Rabbani and P. C. Seville. The influence of formulation components on the aerosolisation properties of spray-dried powders. J. Control. Release 110:130-140 (2005).

309. S. Nagarajan, J. S. Patton, D. B. Bennett, J. Greene, H.-S. Chiang, C. L. M. Stults, G. Venthoye, D. L. Allen, B. L. Hughes, M. Stiff-Torvik, R. K. Wolff, and W. D. Roeder. Pulmonary Administration of Dry Powder Formulations for Treating Infertility, Nektar Therapeutics USA Patent 7,112,341, 2006.

310. H.-Y. Li, H. Neill, R. Innocent, P. Seville, I. Williamson, and J. C. Birchall. Enhanced dispersibility and deposition of spraydried powders for pulmonary gene therapy. J. Drug Target. 11:425-432 (2003).

311. Y.-L. Wong, S. Sampson, W. A. Germishuizen, S. Goonesekera, G. Caponetti, J. Sadoff, B. R. Bloom, and D. Edwards. Drying a tuberculosis vaccine without freezing. Proc. Natl. Acad. Sci. USA 104:2591-2595 (2007).

312. M.-C. Kuo and D. Lechuga-Ballesteros. Dry Powder Compositions Having Improved Dispersivity, USA Patent 6,518,239, 2003.

313. D. Lechuga-Ballesteros, C. Charan, Y. Liang, C. Stults, R. Vehring, and M.-C. Kuo. Designing stable and high performance respirable particles of pharmaceuticals. Respir. Drug Deliv. Proc. IX:565-568 (2004).

314. C. L. Stevenson, D. B. Bennett, and D. Lechuga-Ballesteros. Pharmaceutical liquid crystals: the relevance of partially ordered systems. J. Pharm. Sci. 94:1861-1880 (2005).

315. C. Stevenson, J. E. Hastedt, S. R. Lehrman, H.-S. Chiang, D. Bennett, D. Lesikar, B. Yang, D. Gong, and K. Cabot. Inhalable Spray Dried 4-helix Bundle Protein Powders Having Minimized Aggregation, Nektar Therapeutics USA Patent 6,569,406, 2003.

316. H.-K. Chan and I. Gonda. Solid state characterization of spraydried powders of recombinant human deoxyribonuclease (RhDNase). J. Pharm. Sci. 87:647-654 (1998).

317. J. E. Hastedt, K. Cabot, D. Gong, and D. Hester. Storage Stable Powder Compositions of Interleukin-4 Receptor, Nektar Therapeutics USA Patent 7,172,768, 2007.

318. J. Berggren and G. Alderborn. Effect of polymer content and molecular weight on the morphology and heat- and moistureinduced transformations of spray-dried composite particles of amorphous lactose and poly(vinylpyrrolidone). Pharm. Res. 20:1039-1046 (2003).

319. A. A. Ambike, K. R. Mahadik, and A. Paradkar. Stability study of amorphous valdecoxib. Int. J. Pharm. 282:151-162 (2004).

320. D. O. Corrigan, A. M. Healy, and O. I. Corrigan. The effect of spray drying solutions of bendroflumethiazide/polyethylene glycol on the physicochemical properties of the resultant materials. Int. J. Pharm. 262:125-137 (2003).

321. H.-K. Chan, A. R. Clark, J. C. Feeley, M.-C. Kuo, S. R. Lehrman, K. Pikal-Cleland, D. P. Miller, R. Vehring, and D. Lechuga-Ballesteros. Physical stability of salmon calcitonin spray-dried powders for inhalation. J. Pharm. Sci. 93:792-804 (2004).

322. G. F. Palmieri, G. Bonacucina, P. Di Martino, and S. Martelli. Spray-drying as a method for microparticulate controlled release systems preparation: advantages and limits. I. Watersoluble drugs. Drug Dev. Ind. Pharm. 27:195-204 (2001).

323. J. H. Crowe, J. F. Carpenter, and L. M. Crowe. The role of vitrification in anhydrobiosis. Annu. Rev. Physiol. 60:73-103 (1998).

324. L. Yu. Amorphous pharmaceutical solids: preparation, characterization and stabilization. Adv. Drug Deliv. Rev. 48:27-42 (2001).

325. L. R. Hilden, and K. R. Morris. Physics of amorphous solids. J. Pharm. Sci. 93:3-12 (2004).

326. D. Lechuga-Ballesteros, D. P. Miller, and J. Zhang. Residual water in amorphous solids, measurement and effects on stability. In H. Levine (ed.), Progress in Amorphous Food and Pharmaceutical Systems, The Royal Society of Chemistry, London, 2002, pp. 275-316.

327. P. Gupta and A. K. Bansal. Spray drying for generation of a ternary amorphous system of celecoxib, PVP, and meglumine. Pharm. Dev. Technol. 10:273-281 (2005).

328. A. A. Elkordy, R. T. Forbes, and B. W. Barry. Stability of crystallised and spray-dried lysozyme. Int. J. Pharm. 278:209219 (2004).

329. A. Namaldi, P. Çalik, and Y. Uludag. Effects of spray drying temperature and additives on the stability of serine alkaline protease powders. Dry. Technol. 24:1495-1500 (2006).

330. P. Russo, C. Sacchetti, I. Pasquali, R. Bettini, G. Massimo, P. Colombo, and A. Rossi. Primary microparticles and agglomerates of morphine for nasal insufflation. J. Pharm. Sci. 95:2553-2561 (2006).

331. S. P. Sellers, G. S. Clark, R. E. Sievers, and J. F. Carpenter. Dry powders of stable protein formulations from aqueous solutions prepared using supercritical CO2-assisted aerosolization. J. Pharm. Sci. 90:785-797 (2001).

332. B. Dani, R. Platz, and S. T. Tzannis. High concentration formulation feasibility of human immunoglubulin $\mathrm{G}$ for subcutaneous administration. J. Pharm. Sci. 96:1504-1517 (2007).

333. S. T. Tzannis, and S. J. Prestrelski. Activity-stability considerations of trypsinogen during spray drying: effects of sucrose. J. Pharm. Sci. 88:351-359 (1999).

334. Y.-H. Liao, M. B. Brown, T. Nazir, A. Quader, and G. P. Martin. Effects of sucrose and trehalose on the preservation of the native structure of spray-dried lysozyme. Pharm. Res. 19:18471853 (2002). 
335. A. M. Abdul-Fattah, V. Truong-Le, L. Yee, E. Pan, Y. Ao, D. Kalonia, and M. J. Pikal. Drying-induced variations in physico-chemical properties of amorphous pharmaceuticals and their impact on stability II: Stability of a vaccine. Pharm. Res. 24:715-727 (2007).

336. A. M. Abdul-Fattah, V. Truong-Le, L. Yee, L. Nguyen, D. S. Kalonia, M. T. Cicerone, and M. J. Pikal. Drying-induced variations in physico-chemical properties of amorphous pharmaceuticals and their impact on stability (I): stability of a monoclonal antibody. J. Pharm. Sci. 96:1983-2008 (2007).

337. Y.-H. Liao, M. B. Brown, S. A. Jones, T. Nazir, and G. P. Martin. The effects of polyvinyl alcohol on the in vitro stability and delivery of spray-dried protein particles from surfactantfree HFA 134a-based pressurised metered dose inhalers. Int. J. Pharm. 304:25-39 (2005).

338. X. C. Nguyen, J. D. Herberger, and P. A. Burke. Protein powders for encapsulation: a comparison of spray-freeze drying and spray drying of darbepoetin alfa. Pharm. Res. 21:507-514 (2004).

339. H. R. Costantino, J. D. Andya, P.-A. Nguyen, N. Dasovich, T. D. Sweeney, S. J. Shire, C. C. Hsu, and Y.-F. Maa. Effect of mannitol crystallization on the stability and aerosol performance of a spray-dried pharmaceutical protein, recombinant humanized anti-IgE monoclonal antibody. J. Pharm. Sci. 87:1406-1411 (1998).

340. R. T. Forbes, K. G. Davis, M. Hindle, J. G. Clarke, and J. Maas. Water vapor sorption studies on the physical stability of a series of spray-dried protein/sugar powders for inhalation. J. Pharm. Sci. 87:1316-1321 (1998)

341. R. Vehring. Red-excitation dispersive raman spectroscopy is a suitable technique for solid state analysis of respirable pharmaceutical powders. Appl. Spectrosc. 59:286-292 (2005).

342. L. Yu and $\mathrm{K}$. Ng. Glycine crystallization during spray drying: the $\mathrm{pH}$ effect on salt and polymorphic forms. J. Pharm. Sci. 91:2367-2375 (2002).

343. D. O. Corrigan, A. M. Healy, and O. I. Corrigan. The effect of spray drying solutions of polyethylene glycol (PEG) and lactose/PEG on their physicochemical properties. Int. J. Pharm. 235:193-205 (2002).

344. K. Mosén, K. Bäckström, K. Thalberg, T. Schaefer, A. Axelsson, and H. G. Kristensen. The apparent plasticizing effect of polyethylene glycol (PEG) on the crystallinity of spray dried lactose/PEG composites. Eur. J. Pharm. Biopharm. 64:206-211 (2006).

345. K. Gilani, A. R. Najafabadi, M. Barghi, and M. Rafiee-Tehrani. The effect of water to ethanol feed ratio on physical properties and aerosolization behavior of spray dried cromolyn sodium particles. J. Pharm. Sci. 94:1048-1059 (2005).

346. P. Di Martino, M. Scoppa, E. Joiris, G. F. Palmieri, C. Andres, Y. Pourcelot, and S. Martelli. The spray drying of acetazolamide as method to modify crystal properties and to improve compression behaviour. Int. J. Pharm. 213:209-221 (2001).

347. S. T. Tzannis and S. J. Prestrelski. Moisture effects on proteinexcipient interactions in spray-dried powders. Nature of destabilizing effects of sucrose. J. Pharm. Sci. 88:360-370 (1999).

348. I. G. Davidson, E. J. Langner, S. V. Plowman, and J. A. Blair. Release mechanism of insulin encapsulated in trehalose ester derivative microparticles delivered via inhalation. Int. J. Pharm. 254:211-222 (2003)

349. S. X. Yin, M. Franchini, J. Chen, A. Hsieh, S. Jen, T. Lee, M. Hussain, and R. Smith. Bioavailability enhancement of a COX-2 inhibitor, BMS-347070, from a nanocrystalline dispersion prepared by spray-drying. J. Pharm. Sci. 94:1598-1607 (2005).

350. T. Quattrin, A. Bélanger, N. J. V. Bohannon, and S. L. Schwartz. Efficacy and safety of inhaled insulin (exubera) compared with subcutaneous insulin therapy in patients with type 1 diabetes. Diabetes Care 27:2622-2627 (2004).

351. S. White, D. B. Bennett, S. Cheu, P. W. Conley, D. B. Guzek, S. Gray, J. Howard, R. Malcolmson, J. M. Parker, P. Roberts, N. Sadrzadeh, J. D. Schumacher, S. Seshadri, G. W. Sluggett, C. L. Stevenson, and N. J. Harper. EXUBERA ${ }^{\circledR}$ : pharmaceutical development of a novel product for pulmonary delivery of insulin. Diabetes Technol. Ther. 7:896-906 (2005).
352. N. J. Harper, S. Gray, J. De Groot, J. M. Parker, N. Sadrzadeh, C. Schuler, J. D. Schumacher, S. Seshadri, A. E. Smith, G. S. Steeno, C. L. Stevenson, R. Taniere, M. Wang, and D. B. Bennett. The design and performance of the Exubera ${ }^{\circledR}$ pulmonary insulin delivery system. Diabetes Technol. Ther. 9:S16-S27 (2007).

353. J. S. Skyler, W. T. Cefalu, I. A. Kourides, W. H. Landschulz, C. C. Balagtas, S.-L. Cheng, and R. A. Gelfand. Efficacy of inhaled human insulin in type 1 diabetes mellitus: a randomised proof-of-concept study. Lancet 357:331-335 (2001).

354. D. Lechuga-Ballesteros, M. Kuo, Y. Liang, R. Malcolmson, D. Miller, S. Sekulic, S. Seshadri, C. Stults, T. Tan, V. Joshi, C. Zhen, L. Williams, and D. Bennett. The physcial stability of insulin powder for inhalation. AAPS J. 6:R6137(2004).

355. N. Sadrzadeh, M. J. Glembourtt, and C. L. Stevenson. Peptide drug delivery strategies for the treatment of diabetes. J. Pharm. Sci. 96:1925-1954 (2007).

356. R. Malcolmson, C. De Moor, D. Miller, Y. Liang, C. Zhen, Y. Kim, J. Merchant, D. Bennett, I. Saracovan, and S. Sekulic. Physical properties of bulk insulin powder for inhalation. AAPS J. 6:R6169(2004).

357. C. Dunn and M. P. Curran. Inhaled human insulin (Exubera ${ }^{\circledR}$ ): a review of its use in adult patients with diabetes mellitus. Drugs 66:1013-1032 (2006).

358. W. T. Cefalu and Z. Q. Wang. Clinical research observations with use of exubera in patients with type 1 and 2 diabetes. Diabetes Technol. Ther. 9:S28-S40 (2007).

359. J. Elversson and A. Millqvist-Fureby. Aqueous two-phase systems as a formulation concept for spray-dried protein. Int J. Pharm. 294:73-87 (2005).

360. P. K. Naraharisetti, M. D. N. Lew, Y.-C. Fu, D.-J. Lee, and C.-H. Wang. Gentamicin-loaded discs and microspheres and their modifications: characterization and in vitro release. J. Control. Release 102:345-359 (2005).

361. A. Edris and B. Bergnståhl. Encapsulation of orange oil in a spray dried double emulsion. Nahrung/Food 45:133-137 (2001).

362. P. Kortesuo, M. Ahola, M. Kangas, I. Kangasniemi, A. YliUrpo, and J. Kiesvaara. In vitro evaluation of sol-gel processed spray dried silica gel microspheres as carrier in controlled drug delivery. Int. J. Pharm. 200:223-229 (2000).

363. P. Kortesuo, M. Ahola, M. Kangas, M. Jokinen, T. Leino, L. Vuorilehto, S. Laakso, J. Kiesvaara, A. Yli-Urpo, and M. Marvola. Effect of synthesis parameters of the sol-gelprocessed spray-dried silica gel microparticles on the release rate of dexmedetomidine. Biomaterials 23:2795-2801 (2002).

364. T. Czuryszkiewicz, S. Areva, M. Honkanen, and M. Lindén. Synthesis of sol-gel silica materials providing a slow release of biphosphonate. Colloids Surf., A Physicochem. Eng. Asp. 254:69-74 (2005).

365. F. Iskandar, I. W. Lenggoro, B. Xia, and K. Okuyama Functional nanostructured silica powders derived from colloidal suspensions by sol spraying. J. Nanopart. Res. 3:263-270 (2001).

366. G. P. Alves and M. H. A. Santana. Phospholipid dry powders produced by spray drying processing: structural, thermodynamic and physical properties. Powder Technol. 145:139-148 (2004).

367. L. S. C. Wan, P. W. S. Heng, and C. G. H. Chia. Spray drying as a process for microencapsulation and the effect of different coating polymers. Drug Dev. Ind. Pharm. 18:997-1011 (1992).

368. P. Harjunen, V.-P. Lehto, J. Välisaari, T. Lankinen, P. Paronen, and K. Järvinen. Effects of ethanol to water ratio in feed solution on the crystallinity of spray-dried lactose. Drug Dev. Ind. Pharm. 28:949-955 (2002).

369. L. Koester, P. Mayorga, and V. L. Bassani. Carbamazepine/ $\beta C D / H P M C$ solid dispersions. I. Influence of the spray-drying process and $\beta \mathrm{CD} / \mathrm{HPMC}$ on the drug dissolution profile. Drug Dev. Ind. Pharm. 29:139-144 (2003).

370. L. S. Koester, P. Mayorga, V. P. Pereira, C. L. Petzhold, and V. L. Bassani. Carbamazepine/ $\beta$ CD/HPMC solid dispersions. II. Physical characterization. Drug Dev. Ind. Pharm. 29:145-154 (2003).

371. J. Lee. Drug nano- and microparticles processed into solid dosage forms: physical properties. J. Pharm. Sci. 92:2057-2068 (2003).

372. Y.-L. Lo, J.-C. Tsai, and J.-H. Kuo. Liposomes and disaccharides as carriers in spray-dried powder formulations of superoxide dismutase. J. Control. Release 94:259-272 (2004). 
373. A. Garcia-Arieta, S. Torrado-Santiago, L. Goya, and J. J. Torrado. Spray-dried powders as nasal absorption enhancers of cyanocobalamin. Biol. Pharma. Bull. 24:1411-1416 (2001).

374. B. Boh, E. Knez, and M. Staresinic. Microencapsulation of higher hydrocarbon phase change materials by in situ polymerization. J. Microencapsul. 22:715-735 (2005).

375. H. Takeuchi, S. Nagira, H. Yamamoto, and Y. Kawashima. Solid dispersion particles of amorphous indomethacin with fine porous silica particles by using spray-drying method. Int. J. Pharm. 293:155-164 (2005).

376. H. Takeuchi, S. Nagira, H. Yamamoto, and Y. Kawashima. Solid dispersion particles of tolbutamide prepared with fine silica particles by the spray-drying method. Powder Technol. 141:187195 (2004).

377. A. A. Ambike, K. R. Mahadik, and A. Paradkar. Spray-dried amorphous solid dispersions of simvastatin, a low tg drug: in vitro and in vivo evaluations. Pharm. Res. 22:990-998 (2005).

378. C. G. Oster, and T. Kissel. Comparative study of DNA encapsulation into PLGA microparticles using modified double emulsion methods and spray drying techniques. J. Microencapsul. 22:235-244 (2005).

379. J. O.-H. Sham, Y. Zhang, W. H. Finlay, W. H. Roa, and R. Löbenberg. Formulation and characterization of spray-dried powders containing nanoparticles for aerosol delivery to the lung. Int. J. Pharm. 269:457-467 (2004).

380. R. O. Cook, R. K. Pannu, and I. W. Kellaway. Novel sustained release microspheres for pulmonary drug delivery. J. Control. Release 104:79-90 (2005).

381. F. Iskandar, L. Gradon, and K. Okuyama. Control of the morphology of nanostructured particles prepared by the spray drying of a nanoparticle sol. J. Colloid Interface Sci. 265:296303 (2003).

382. K. Okuyama, M. Abdullah, I. W. Lenggoro, and F. Iskandar. Preparation of functional nanostructured particles by spray drying. Adv. Powder Technol. 17:587-611 (2006).

383. A. Grenha, B. Seijo, and C. Remuñán-López. Microencapsulated chitosan nanoparticles for lung protein delivery. Eur. J. Pharm. Sci. 25:427-437 (2005).

384. A. Lind, C. du Fresne von Hohenesche, J.-H. Smått, M. Lindén, and K. K. Unger. Spherical silica agglomerates possessing hierarchical porosity prepared by spray drying of MCM-41 and MCM-48 nanospheres. Microporous Mesoporous Mater. 66:219-227 (2003).

385. F. Iskandar, H. Chang, and K. Okuyama. Preparation of microencapsulated powders by an aerosol spray method and their optical properties. Adv. Powder Technol. 14:349-367 (2003).

386. F. Oneda and M. I. Ré. The effect of formulation variables on the dissolution and physical properties of spray-dried microspheres containing organic salts. Powder Technol. 130:377-384 (2003).

387. A. R. Pohlmann, V. Weiss, O. Mertins, N. Pesce da Silveira, and S. S. Guterres. Spray-dried indomethacin-loaded polyester nanocapsules and nanospheres: development, stability evaluation and nanostructure models. Eur. J. Pharm. Sci. 16:305-312 (2002).

388. R. C. R. Beck, A. R. Pohlmann, E. V. Benvenutti, T. Dalla Costa, and S. S. Guterres. Nanostructure-coated diclofenacloaded microparticles: preparation, morphological characteri- zation, in vitro release and in vivo gastrointestinal tolerance. J. Braz. Chem. Soc. 16:1233-1240 (2005).

389. R. C. R. Beck, S. E. Haas, S. S. Guterres, M. I. Ré, E. V. Benvenutti, and A. R. Pohlmann. Nanoparticle-coated organicinorganic microparticles: experimental design and gastrointestinal tolerance evaluation. Quím. Nova 29:990-996 (2006).

390. S. R. Schaffazick, A. R. Pohlmann, G. Mezzalira, and S. S Guterres. Development of nanocapsule suspensions and nanocapsule spray-dried powders containing melatonin. J. Braz. Chem. Soc. 17:562-569 (2006).

391. P. Tewa-Tagne, G. Degobert, S. Briançon, C. Bordes, J.-Y Gauvrit, P. Lanteri, and H. Fessi. Spray-drying nanocapsules in presence of colloidal silica as drying auxiliary agent: formulation and process variables optimization using experimental designs. Pharm. Res. 24:650-661 (2007).

392. R. C. R. Beck, A. R. Pohlmann, and S. S. Guterres. Nanoparticle-coated microparticles: preparation and characterization. J. Microencapsul. 21:499-512 (2004).

393. P. Tewa-Tagne, S. Briançon, and H. Fessi. Spray-dried microparticles containing polymeric nanocapsules: formulation aspects, liquid phase interactions and particles characteristics. Int. J. Pharm. 325:63-74 (2006).

394. T. Hansen, P. Holm, and K. Schultz. Process characteristics and compaction of spray-dried emulsions containing a drug dissolved in lipid. Int. J. Pharm. 287:55-66 (2004).

395. T. Ozeki, S. Beppu, T. Mizoe, Y. Takashima, H. Yuasa, and H. Okada. Preparation of polymeric submicron particlecontaining microparticles using a 4-fluid nozzle spray drier. Pharm. Res. 23:177-183 (2006).

396. T. Ozeki, S. Beppu, T. Mizoe, Y. Takashima, H. Yuasa, and H. Okada. Preparation of two-drug composite microparticles to improve the dissolution of insoluble drug in water for use with a 4-fluid nozzle spray drier. J. Control. Release 107:387-394 (2005).

397. D. B. Bennet, T. K. Brewer, and R. M. Platz. Spray Drying Process for Preparing Dry Powders, Inhale Therapeutic Systems, Inc. International Patent WO 01/00312 A1, 2001.

398. L. Gradoń, S. Janeczko, M. Abdullah, F. Iskandar, and K. Okuyama. Self-organization kinetics of mesoporous nanostructured particles. AIChE J. 50:2583-2593 (2004).

399. F. Iskandar, Mikrajuddin, and K. Okuyama. In situ production of spherical silica particles containing self-organized mesopores. Nano Lett. 1:231-234 (2001).

400. F. Iskandar, Mikrajuddin, and K. Okuyama. Controllability of pore size and porosity on self-organized porous silica particles. Nano Lett. 2:389-392 (2002).

401. X.-Y. Shi and T.-W. Tan. Preparation of chitosan/ethylcellulose complex microcapsule and its application in controlled release of vitamin D2. Biomaterials 23:4469-4473 (2002).

402. M. Kempf, B. Mandal, S. Jilek, L. Thiele, J. Vörös, M. Textor, H. P. Merkle, and E. Walter. Improved stimulation of human dendritic cells by receptor engagement with surface-modified microparticles. J. Drug Target. 11:11-18 (2003).

403. M. Vajdy and D. T. O'Hagan. Microparticles for intranasal immunization. Adv. Drug Deliv. Rev. 51:127-141 (2001).

404. C. Kusonwiriyawong, K. Atuah, O. H. Alpar, H. P. Merkle, and E. Walter. Cationic stearylamine-containing biodegradable microparticles for DNA delivery. J. Microencapsul. 21:25-36 (2004). 